\title{
Weddell Sea Export Pathways from Surface Drifters
}

\author{
MAdELEINE K. Youngs AND ANDREW F. THOMPSON \\ Environmental Science and Engineering, California Institute of Technology, Pasadena, California \\ M. MAR FLEXAS \\ Jet Propulsion Laboratory, California Institute of Technology, Pasadena, California \\ KAREN J. HEYWOOD \\ School of Environmental Sciences, University of East Anglia, Norwich, United Kingdom
}

(Manuscript received 28 May 2014, in final form 16 January 2015)

\begin{abstract}
The complex export pathways that connect the surface waters of the Weddell Sea with the Antarctic Circumpolar Current influence water mass modification, nutrient fluxes, and ecosystem dynamics. To study this exchange, 40 surface drifters, equipped with temperature sensors, were released into the northwestern Weddell Sea's continental shelf and slope frontal system in late January 2012. Comparison of the drifter trajectories with a similar deployment in early February 2007 provides insight into the interannual variability of the surface circulation in this region. Observed differences in the 2007 and 2012 drifter trajectories are related to a variable surface circulation responding to changes in wind stress curl over the Weddell Gyre. Differences between northwestern Weddell Sea properties in 2007 and 2012 include 1) an enhanced cyclonic wind stress forcing over the Weddell Gyre in 2012; 2) an acceleration of the Antarctic Slope Current (ASC) and an offshore shift of the primary drifter export pathway in 2012; and 3) a strengthening of the Coastal Current (CC) over the continental shelf in 2007. The relationship between wind stress forcing and surface circulation is reproduced over a longer time period in virtual drifter deployments advected by a remotely sensed surface velocity product. The mean offshore position and speed of the drifter trajectories are correlated with the wind stress curl over the Weddell Gyre, although with different temporal lags. The drifter observations are consistent with recent modeling studies suggesting that Weddell Sea boundary current variability can significantly impact the rate and source of exported surface waters to the Scotia Sea, a process that determines regional chlorophyll distributions.
\end{abstract}

\section{Introduction}

The surface circulation of the northwestern Weddell Sea impacts both local and remote ecosystem dynamics. Boundary currents, such as the Antarctic Slope Current (ASC) and the Antarctic Coastal Current (CC), described below, transport Antarctic krill from spawning areas near the coast to the Scotia Sea (Hofmann et al. 1998; Murphy et al. 2004; Thorpe et al. 2004, 2007). Furthermore, shelf waters around the Antarctic Peninsula and the South Shetland Islands exhibit elevated concentrations of iron (Fitzwater et al. 2000; Ardelan et al. 2010; Frants et al.

\footnotetext{
Corresponding author address: Madeleine K. Youngs, Environmental Science and Engineering, California Institute of Technology, MC 131-24, Pasadena, CA 91125.

E-mail: myoungs@caltech.edu
}

2012a,b) that promote biological productivity in regions that are replete in macronutrients but limited in micronutrients (Martin et al. 1990; Fitzwater et al. 2000). Advection of iron from the continental shelves of the Weddell Sea to the Scotia Sea is a key reason for the enhancement of surface chlorophyll in eastern Drake Passage (Korb et al. 2004; Zhou et al. 2010; Thompson and Youngs 2013; Wadley et al. 2014). Furthermore, variability in these boundary currents mediates exchange between shelf and open-ocean waters. Changes in the surface circulation that modify either the Weddell Sea residence time or the flux of iron are likely to influence the timing and distribution of primary production in the Scotia Sea.

Boundary current variability arises from either timedependent forcing and tidal motions or intrinsic variability related to dynamic instabilities. Large-scale atmospheric 
forcing in the Southern Hemisphere is dominated by the southern annular mode (SAM), which is manifested by a strengthening and a southward shift of Southern Hemisphere westerlies when the SAM is in its positive phase (Marshall et al. 2004). Over the last $60 \mathrm{yr}$ the SAM index has, on top of natural variability, increased by one standard deviation, largely because of ozone depletion and other anthropogenic forcings (Marshall et al. 2004; Thompson and Solomon 2002). Much of the work on the oceanic response to the SAM has focused on the Antarctic Circumpolar Current (ACC) (Hall and Visbeck 2002; Sen Gupta and England 2006; Meredith and Hogg 2006), although Simpkins et al. (2012) have linked Antarctic sea ice extent to the SAM index as well. Recently O'Kane et al. (2013) showed that variations in the Southern Ocean zonal wind stress is dominated by their first three empirical orthogonal functions, with SAM captured in the first mode ( $33 \%$ of the variance) and $\mathrm{El}$ Niño-Southern Oscillation (ENSO) expressed in the second and third modes (17.3 and $12.1 \%$ of the variance).

Through the analysis of two surface drifter deployments and a decade of surface velocity observations from the Ocean Surface Current Analyses-Real Time (OSCAR) product (Bonjean and Lagerloef 2002), we conclude that changes in surface wind stress modify the surface circulation of the northwestern Weddell Sea. Critically, these changes are concentrated in the Weddell Sea's narrow boundary currents, especially the ASC $^{1}$ and the more shoreward CC. Renner et al. (2012) first explored the dependence of surface export on atmospheric forcing in this region using a coupled sea iceocean model (ORCA025-LIM2). They found that virtual drifter trajectories released over a 43-yr period show a negative correlation between the SAM index and travel times to South Georgia Island. The reduced export time during periods of increased westerlies was attributed to a change in the surface currents, providing a tendency for more drifters to move across the South Scotia Ridge into the Scotia Sea, instead of through Bransfield Strait. However, the simulated drifter trajectories were unable to capture the strong mesoscale variability associated with the ASC in this region (Thompson et al. 2014).

The ASC is generally found over or just offshore of the shelf break (Gill 1973; Jacobs 1991; Whitworth et al. 1998) and can migrate onshore/offshore in response to tidal fluctuations (Whitworth and Orsi 2006) or seasonal

\footnotetext{
${ }^{1}$ We note that the Antarctic Slope Front typically refers to the subsurface water mass gradients that give rise to the frontal current. The surface drifter data do not provide vertical information of the water column structure. For consistency we refer to the ASC as the strong surface current(s) found over the continental slope.
}

fluctuations in the wind stress (Su et al. 2014). The CC, on the other hand, is generally found over the continental shelf and is weaker than the ASC. The mean flows of the ASC and the CC move primarily along contours of constant depth (or constant potential vorticity $f / h$; Heywood et al. 2004). Together, the CC and the ASC regulate exchange between shelf waters and the open ocean (Nøst et al. 2011; Stewart and Thompson 2013). Strong mean flows may provide a barrier to cross-shelf/ slope exchange, while variability in these currents offers a mechanism to promote exchange. Lateral exchange via mesoscale eddies may contribute significantly to the onshore fluxes of warm Modified Circumpolar Deep Water (MCDW) and the formation of Weddell Sea Deep Water (WSDW; Whitworth et al. 1998; Stewart and Thompson 2013).

In recognition of its importance as a gateway for exchange between the Weddell and Scotia Seas, the structure of the ASC and the CC has been extensively studied in this region. Heywood et al. (2004) used hydrographic data to determine the paths of the ASC and CC near the South Scotia Ridge with a specific goal of tracking the currents as they entered the complex topography of the Weddell Scotia Confluence (Patterson and Sievers 1980; Whitworth et al. 1994). The ASC closely follows the $1000-1500-\mathrm{m}$ isobaths, traveling along a topographically steered route northward to the ACC. Heywood et al. (2004) also identified a third offshore frontal current, distinct from the ASC, and labeled it the Weddell Front (WF). The WF follows the 3000-m isobath around Powell basin to the south of the South Orkney Plateau. Palmer et al. (2012) identified the ASC in a $50^{\circ} \mathrm{W}$ section south of the Hesperides Trough and at a 2100-mdeep gap in the South Scotia Ridge at $61.2^{\circ} \mathrm{S}, 51^{\circ} \mathrm{W}$ and found that the ASC travels cyclonically around the Hesperides Trough and flows into the Scotia Sea through several relatively shallow gaps west of the Orkney Plateau.

Most observational studies of the CC and ASC have relied on cross-front hydrographic sections to piece together the path of the boundary currents. Lagrangian instruments offer a more direct representation of surface export pathways, with the compromise of a reduced suite of measurements, recording position, and temperature only. In 2007, the Antarctic Drifter Experiment: Links to Isobaths and Ecosystems (ADELIE) project released 40 surface drifters along the World Ocean Circulation Experiment (WOCE) SR04 section (Fig. 1), (Thompson et al. 2009). The drifter trajectories revealed strong steering by topography (Thompson et al. 2009) and confirmed the large-scale structure of the export pathways of the ASC and the CC proposed by Heywood et al. (2004). Finer details of the circulation included the merger of the ASC with the CC north of Joinville Ridge 

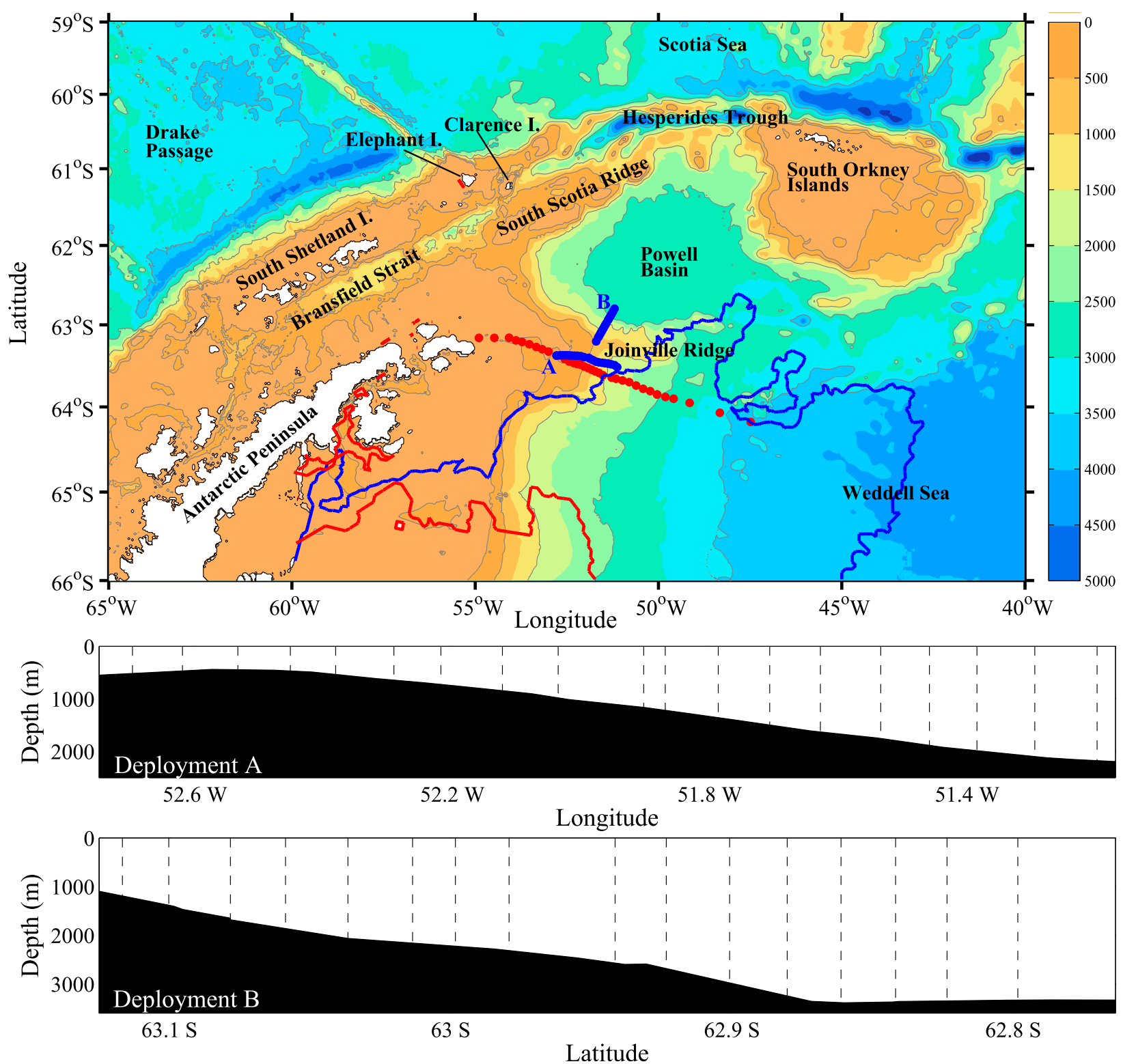

FIG. 1. The GENTOO study region. (top) Circles show the deployment locations of the GENTOO (2012, blue) and ADELIE (2007, red) drifters. Deployments along transects A and B of the GENTOO study are labeled. The $10 \%$ sea ice concentration line is drawn for the date of deployment for both the ADELIE (red) and GENTOO (blue) studies. Bathymetry is colored and the 500-, 1000-, 2000-, 3000-, and 4000-m isobaths are contoured. The bathymetry is from Smith and Sandwell (1997). (bottom) Depth of the deployment positions (dashed lines) along transects A and B in 2012.

and a subsequent divergence at the base of the South Scotia Ridge (SSR). The trajectories also indicated the potential for multiple routes over the SSR before merging to describe a cyclonic flow around the western end of Hesperides Trough.

Since the ADELIE study provided only one realization of the surface circulation, this motivated a repeat of the 2007 drifter deployment to examine the robustness of the export pathways. The Gliders: Excellent New Tools for Observing the Ocean (GENTOO) project was conducted in January 2012 in the northwestern Weddell Sea and involved the deployment of ocean gliders, a ship-based hydrographic survey, and surface drifter deployments. This study will focus on the surface drifter data, including a comparative analysis with the 2007 ADELIE drifter trajectories. Section 2 describes the drifter data and other datasets used in our analysis. We compare drifter trajectories and statistical properties of the GENTOO and ADELIE deployments in section 3. In section 4a, we present the case for a link 

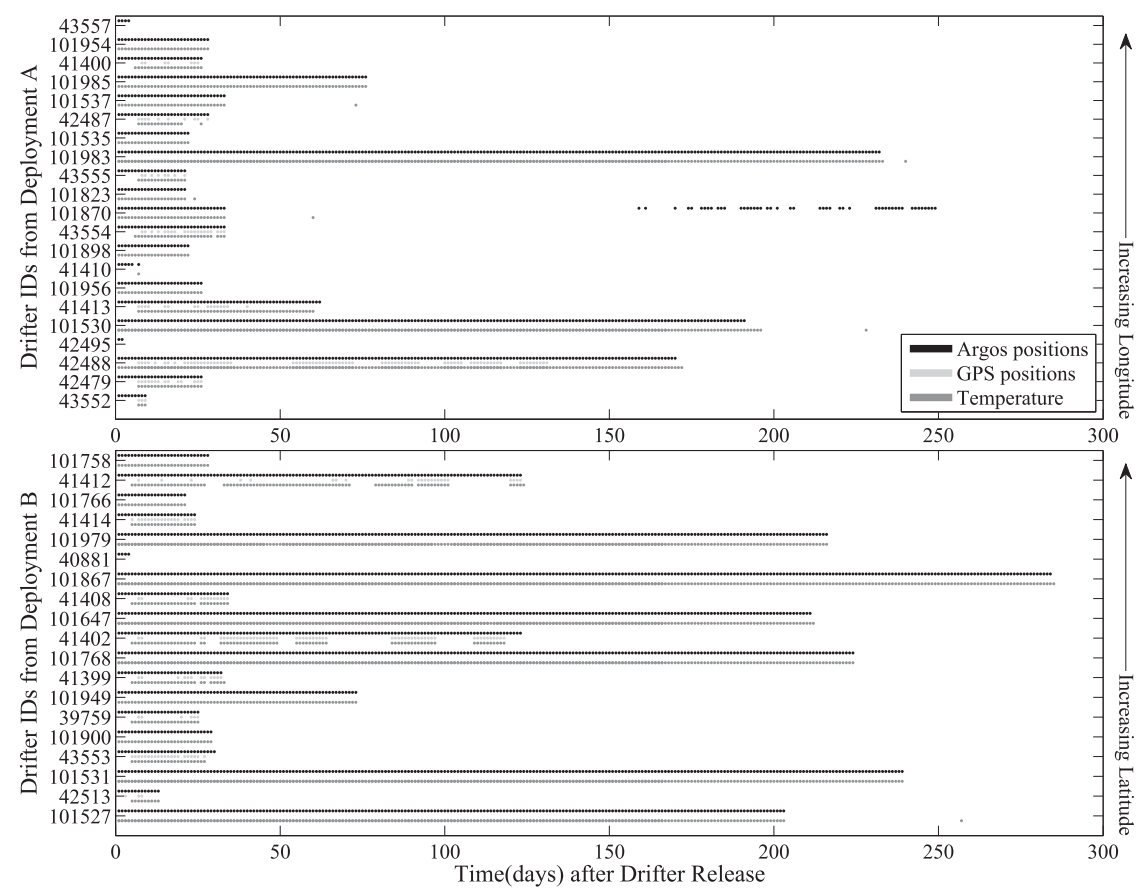

FIG. 2. Summary of the GENTOO drifter data. Bars represent the time series of Argos (black), sea surface temperature (gray), and GPS (light gray) positions. 20 of the 40 surface drifters were equipped with GPS transmitters.

between atmospheric wind patterns, sea ice variability, and surface circulation in the northwestern Weddell Sea. Discussion and conclusions are presented in section 5.

\section{Data}

\section{a. Drifter data}

On 24 and 26 January 2012, 40 ClearSat-15 minidrogue drifters were released across the continental shelf and slope in the northwestern Weddell Sea from the Royal Research Ship (RRS) James Clark Ross. Figure 1 summarizes the deployment location of both the GENTOO drifter deployment in 2012 (blue) and the ADELIE deployment in 2007 (red); for details of the latter, see Thompson et al. (2009). While the ADELIE drifters were deployed across the continental shelf and slope to a depth of $\sim 4000 \mathrm{~m}$, the extent of the GENTOO release was curtailed by the northward extent of the sea ice edge. During GENTOO, 21 drifters were released between depths of 475 and $2300 \mathrm{~m}$ along WOCE section SR04, labeled transect A in Fig. 1, with $\sim 5$-km spacing. The remaining 19 drifters were deployed along transect $\mathrm{B}$, with a tighter spacing of $2 \mathrm{~km}$ between depths of 850 and $3447 \mathrm{~m}$ (Fig. 1). Figure 1 also shows the sea ice extent, given as the $10 \%$ ice concentration contour, on 24 January 2012 (blue) and 8 February 2007 (red).

The drifter data are archived with the Global Drifter Program (www.aoml.noaa.gov/phod/dac/gdp.html). All
GENTOO and ADELIE drifters were drogued to a depth of $15 \mathrm{~m}$ as standardized during WOCE. Surface velocities are calculated from the trajectories using 6-hourly subsamples following the method of Hansen and Poulain (1996). This process includes a low-pass filter with a 38-h cutoff to remove tidal and inertial oscillations (Falco et al. 2000). Following Niiler et al. (1995), the expected velocity, or "slip," imparted to a drifter from the surface winds is less than $2 \mathrm{~cm} \mathrm{~s}^{-1}$ relative to the water for wind velocities up to $20 \mathrm{~m} \mathrm{~s}^{-1}$ while the drogue is still attached.

Figure 2 shows the available data from each drifter in 2012. Black dots represent Argos location fixes, while light gray dots represent GPS location fixes; gray dots represent a temperature measurement (cf. Table 1 in Thompson et al. 2009). All 80 of the GENTOO and ADELIE drifters transmitted position data via the Argos satellite system. The Argos fixes were transmitted approximately once an hour with an accuracy of between 150 and $1000 \mathrm{~m}$ (Lumpkin and Pazos 2007). To improve upon this accuracy, 20 drifters in each study were also equipped with GPS transmitters. While the GPS fixes are more accurate, with an error as small as $25 \mathrm{~m}$, the available GPS data were sparser in 2012 (Fig. 2; Thompson et al. 2009). The surface floats on the mini-drogue drifters used in 2012 were smaller than the surface floats on the drifters used in 2007, leaving them more susceptible to icing that restricted GPS communication (G. Williams 2012, personal communication). All GENTOO and ADELIE drifters 
were also equipped with a thermistor with an accuracy of $0.1^{\circ} \mathrm{C}$ (Hansen and Poulain 1996).

Drifter trajectories and drogue strain data were inspected visually to determine loss of drogue. During the GENTOO deployment, loss of a drifter drogue typically resulted in a loss of transmission on the same day. Portions of drifter trajectories that occurred without a drogue are not used in this analysis. A close examination of the causes of drifter termination is provided in Lumpkin et al. (2012).

\section{b. Additional data}

Sea ice concentrations were provided by AMSR-E data in 2007 and SSMIS sea ice concentrations from 2012 as the AMSR-E satellite failed in late 2011. These datasets can be found online (at www.iup.uni-bremen.de/ seaice/amsr/ and www.iup.uni-bremen.de:8084/ssmis/index. $\mathrm{html}$, respectively; Spreen et al. 2008). To complement the velocity fields obtained from the surface drifters, we used the OSCAR remotely sensed surface (average of 0-30-m depth) velocity product obtained online (from http:// podaac.jpl.nasa.gov). OSCAR data are available on a $1 / 3^{\circ} \times 1 / 3^{\circ}$ grid with one snapshot approximately every 5 days. This product computes global surface velocities using sea surface height, wind, and temperature data and was validated using Global Drifter Program surface drifters (Bonjean and Lagerloef 2002; Johnson et al. 2007).

Near-surface wind stress data (monthly averaged) were obtained from the ERA-Interim atmospheric reanalysis (Simmons et al. 2007). ERA-Interim accounts for the presence of sea ice by modifying the drag coefficient that governs the momentum transfer into the ocean (Dee et al. 2011). While our primary focus will be on the relationship between local wind stress curl and the surface circulation, we will also consider larger-scale connections with climate variability using times series of SAM and ENSO. Our analysis employs monthly estimates of the SAM index calculated from global observations and reported online (at www.antarctica.ac. uk/met/gjma/sam.html; Marshall 2003). We also consider ENSO variability using the Oceanic Niño Index (ONI; from www.cpc.ncep.noaa.gov/products/analysis_ monitoring/ensostuff/ensoyears.shtml). The ONI is a 3month running average of ERSST.v3b sea surface temperature (SST) anomalies in the Niño-3.4 region $\left(5^{\circ} \mathrm{N}-5^{\circ} \mathrm{S}, 120^{\circ}-170^{\circ} \mathrm{W}\right)$.

\section{Surface drifter analysis: GENTOO and ADELIE comparison}

\section{a. Drifter trajectories}

Figure 3 shows filtered drifter trajectories from both the GENTOO (2012) and ADELIE (2007) deployments for the purpose of comparison. Because the ADELIE drifters were deployed over a greater longitudinal extent than the GENTOO drifters, in this study we focus our comparison on drifters that share common deployment longitudes along transect A (Fig. 3b). Immediately after deployment in 2012, the GENTOO drifters followed the western boundary of Powell basin. They subsequently split into two main cores over the 1000- and 2000-m isobaths along the southern boundary of the SSR (Fig. 3a). On 20 February, the drifters shifted rapidly northward over the SSR, crossing $f / h$ contours. Along the northern boundary of the SSR, topographic control resumed and the drifters moved cyclonically around the western portion of Hesperides Trough and then entered the Scotia Sea through multiple gaps in the SSR. Afterward, the drifters were entrained in the strong frontal currents of the ACC and drifted eastward (Thompson and Youngs 2013).

Comparing drifter trajectories in 2007 and 2012 (Fig. 3b), the ADELIE drifters occupied a region shoreward of the GENTOO drifters. A stagnation point at the base of the SSR was a key feature of the ADELIE trajectories, which was not observed in the GENTOO trajectories. During ADELIE, the trajectories were partitioned between those that entered Bransfield Strait, those that were entrained in a standing eddy, and those that traveled eastward along the SSR. In contrast to the ADELIE trajectories, no drifters entered Bransfield Strait in 2012, and only a single GENTOO drifter was entrained in the standing eddy south of Clarence Island (Fig. 3b).

\section{b. Statistics}

Differences between the two drifter deployments also extend to statistical assessments of the trajectories. Table 1 summarizes drifter statistics from both deployments as well as subgroups of each deployment. Diagnostics used to characterize the trajectories include (i) the number of and time for drifters to cross $60^{\circ} \mathrm{S}$ and (ii) the isobath, or water column depth at a given drifter position, averaged over time and all trajectories for each deployment. The former is useful since all drifters that are carried north of $60^{\circ} \mathrm{S}$ left the Weddell Sea, and as such it represents a residence time. The latter is a proxy for the core of the ASC. The two drifter groups that are best suited for comparison are the GENTOO drifters released along transect A and the subset of the ADELIE drifters released in the same longitude band. Comparing just these drifters, a greater number of GENTOO drifters crossed $60^{\circ} \mathrm{S}$ despite a more northward sea ice extent in 2012. The GENTOO drifters experienced a longer lifespan, although the standard deviation exceeds the mean. The GENTOO drifters also have a deeper mean isobath at $1910 \pm 1256 \mathrm{~m}$ as compared with $1496 \pm 1110 \mathrm{~m}$ for the ADELIE deployment, suggesting a more offshore location of the ASC in 2012. 

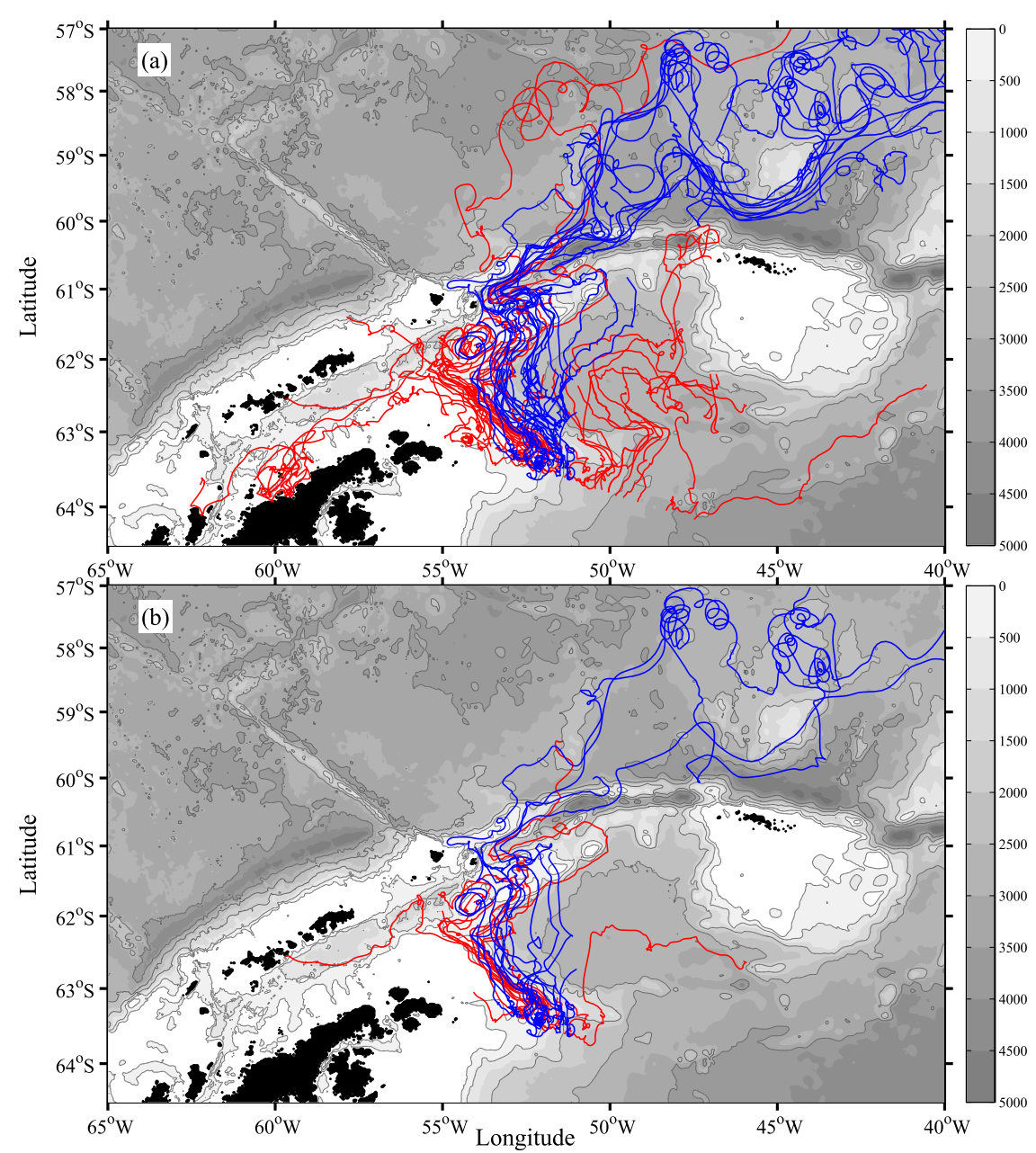

FIG. 3. (a) Filtered trajectories of the $\operatorname{ADELIE~(2007,~red)~and~GENTOO~(2012,~blue)~}$ drifters. (b) Filtered trajectories of the GENTOO (blue) and ADELIE drifters (red) that were deployed within the same longitude band along transect A. The 500-, 1000-, 2000-, 3000-, and 4000-m isobaths are contoured.

Comparing the deployment A subsets, the GENTOO drifters experienced shorter residence times in the Weddell Sea (Table 1). For ADELIE, it took 74 days for the lone drifter to cross $60^{\circ} \mathrm{S}$, but for GENTOO, it took an average of $65 \pm 7$ days. These values are based on a small sample size, but they do agree with the numerical results of Renner et al. (2012). In agreement with the complete dataset, the mean isobath of the GENTOO A drifters is $2190 \pm 1297 \mathrm{~m}$, while the average of the ADELIE subset is $1048 \pm 592 \mathrm{~m}$.

Drifter velocities are calculated from the filtered drifter trajectories using a finite difference method between neighboring location fixes. Velocities are gridded into bins of $0.4^{\circ}$ longitude and $0.2^{\circ}$ latitude, so that bins are roughly square at this latitude (Thompson et al. 2009). The northern extent of the velocity grid is $60^{\circ} \mathrm{S}$ to avoid contamination from the substantially larger ACC velocities. Although more refined methods of calculating the mean velocity fields exist (e.g., Koszalka and LaCasce 2010; LaCasce 2008), the binned means are used for simplicity. The time-mean velocity $\overline{\mathbf{u}}(\mathbf{x})$ is calculated from the binned velocities if the bin has greater than four independent measurements. Residual velocity vectors $\mathbf{u}^{\prime}(\mathbf{x}, t)$ are calculated as the difference between the instantaneous velocities and the binned average:

$$
\mathbf{u}^{\prime}(\mathbf{x}, t)=\mathbf{u}(\mathbf{x}, t)-\overline{\mathbf{u}}(\mathbf{x}),
$$

where $\overline{\mathbf{u}}(\mathbf{x})$ is the mean velocity vector of the bin in which $\mathbf{u}(\mathbf{x}, t)$ is located (LaCasce 2008; Bauer et al. 1998).

Statistical characterization of the drifter trajectories requires an estimate of independent velocity observations. Velocities are considered independent if they are separated by the Lagrangian time scale $T$ or longer. 
TABLE 1. Summary of drifter statistics: number of drifters, mean and standard deviation of drifter lifespan, number and percentage of drifters that cross $60^{\circ} \mathrm{S}$, and mean and standard deviation of drifter residence time (time between deployment and crossing of $60^{\circ} \mathrm{S}$ ). Statistics are calculated for all the ADELIE drifters, the subset of ADELIE drifters released within the GENTOO deployment band, the entire GENTOO deployment and deployment along transects A and B separately. When three values are shown, the highest and lowest are the $95 \%$ confidence intervals.

\begin{tabular}{|c|c|c|c|c|c|c|}
\hline & ADELIE & $\begin{array}{l}\text { ADELIE } \\
\text { subset }\end{array}$ & $\begin{array}{l}\text { ADELIE } \\
\text { OSCAR }\end{array}$ & GENTOO & $\begin{array}{l}\text { GENTOO } \\
\text { transect A }\end{array}$ & $\begin{array}{c}\text { GENTOO } \\
\text { OSCAR }\end{array}$ \\
\hline Total number of drifters & 39 & 18 & 40 & 36 & 21 & 40 \\
\hline Drifter lifespan (days) & 56 & 43 & (47) $52(57)$ & 70 & 51 & (149) $150(150)$ \\
\hline Standard deviation (days) & 47 & 31 & (15) 19 (24) & 82 & 65 & (0) $0.5(7)$ \\
\hline No. crossing $60^{\circ} \mathrm{S}$ & 3 & 1 & (0) $0.5(2)$ & 11 & 3 & (23) $28(32)$ \\
\hline Percentage crossing $60^{\circ} \mathrm{S}$ & $7.5 \%$ & $5.6 \%$ & $(0 \%) 1.3 \%(5 \%)$ & $28 \%$ & $14 \%$ & $(58 \%) 70 \%(80 \%)$ \\
\hline Residence time (days) & 68 & 74 & (79) $83(88)$ & 60 & 65 & (111) 117 (124) \\
\hline Standard deviation (days) & 8 & 0 & (0) $0.5(3)$ & 6 & 7 & (19) $23(26)$ \\
\hline Mean isobath (m) & 1496 & 1048 & (1695) 1798 (1927) & 1901 & 2190 & (2377) 2494 (2599) \\
\hline Standard deviation (m) & 1110 & 592 & (837) $921(988)$ & 1256 & 1297 & $(368) 456(531)$ \\
\hline
\end{tabular}

Determination of $T$ requires the calculation of the eddy diffusivity $\kappa$, which under the assumption of a homogeneous and stationary flow is defined as

$$
\kappa=\lim _{t \rightarrow \infty} \varkappa, \quad \varkappa(t) \equiv \int_{0}^{t} R(\tau) d t
$$

Here, $R(\tau)$ is the Lagrangian autocovariance of the eddy velocity, and $\tau$ is the time lag (Bauer et al. 1998; LaCasce 2008; Thompson et al. 2009; Klocker et al. 2012b). The Lagrangian time scale $T$ is then calculated using the eddy velocity variance $\sigma^{2}$, such that $T=\kappa / \sigma^{2}$ (Bauer et al. 1998; Falco et al. 2000). The Lagrangian length scale $L$ is calculated by multiplying the Lagrangian time scale $T$ by the root-mean-square eddy velocity. The binned velocities are then recalculated, only keeping velocity observations separated by a time greater than $T$. The Lagrangian autocovariance (not shown) exhibits the canonical negative lobe after its first zero crossing, which artificially suppresses $\kappa$ if the integral in (2) is carried out over too short a time period (Klocker et al. 2012a,b). Our calculation of $\kappa$ involves an integration over a time sufficiently longer than this initial negative lobe. Based on the work of Klocker et al. (2012a), we recognize that the deployment of only 40 surface drifters is likely to result in eddy diffusivities with considerable error; however, this statistical diagnostic provides a useful comparison between the ADELIE and GENTOO deployments.

The values of $T_{u, v}$, the Lagrangian length scales $L_{u, v}$, the velocity variances $\sigma^{2}$, and the eddy diffusivities $\kappa$, calculated for GENTOO and ADELIE drifters in the zonal $u$ and meridional $v$ directions, are given in Table 2 . The table also provides estimates of these statistics after rotating velocities into local along- and across-bathymetry components (approximately contours of $f / h$; see Thompson et al. 2009). The values presented in Table 2 differ from Thompson et al. (2009) because they are computed using different average velocity fields. In this study, historical drifter trajectories are not used in the calculation of the average field, but velocities from the new GENTOO data are included. In both geographic and $f / h$ coordinates, the decorrelation time and length scales are shorter for the GENTOO deployment. On the other hand, the velocity variances are similar, indicating that the variability experienced by the drifters was comparable. The shorter decorrelation scales result in weaker eddy diffusivities from the 2012 drifters. A stronger mean flow, as in 2012, will advect mesoscale features more rapidly along the continental slope, which will suppress either $L$ or the decorrelation time scale as eddies spend less time at any

TABLE 2. Lagrangian time $T$ (days) and length scales $L(\mathrm{~km})$, velocity variances $\left\langle u^{\prime 2}, v^{\prime 2}\right\rangle\left(\mathrm{cm}^{2} \mathrm{~s}^{-2}\right)$, where \langle\rangle indicates a temporal and spatial average, and eddy diffusivities $\kappa\left(10^{6} \mathrm{~cm}^{2} \mathrm{~s}^{-2}\right)$. Statistics, calculated from (1) and (2), are provided for the GENTOO and ADELIE deployment as well as the combined trajectories.

\begin{tabular}{|c|c|c|c|c|c|c|c|c|}
\hline Geographic & $T_{u}$ & $T_{v}$ & $L_{u}$ & $L_{v}$ & $\left\langle u^{\prime 2}\right\rangle$ & $\left\langle v^{\prime 2}\right\rangle$ & $\kappa_{u}$ & $\kappa_{v}$ \\
\hline ADELIE & 0.51 & 0.76 & 3.29 & 5.07 & 55.9 & 59.5 & 2.51 & 3.87 \\
\hline GENTOO & 0.31 & 0.56 & 1.97 & 3.64 & 54.3 & 56.5 & 1.45 & 2.73 \\
\hline Combined & 0.42 & 0.67 & 2.69 & 4.42 & 55.1 & 58.2 & 2.02 & 3.39 \\
\hline$f / h$ & $T_{\text {along }}$ & $T_{\text {across }}$ & $L_{\text {along }}$ & $L_{\text {across }}$ & $\left\langle u_{\text {along }}^{\prime 2}\right\rangle$ & $\left\langle\boldsymbol{v}_{\text {across }}^{\prime 2}\right\rangle$ & $\kappa_{\text {along }}$ & $\kappa_{\text {across }}$ \\
\hline ADELIE & 0.66 & 0.46 & 4.59 & 2.99 & 64.7 & 56.6 & 3.71 & 2.26 \\
\hline GENTOO & 0.24 & 0.34 & 1.78 & 2.21 & 74.0 & 56.5 & 1.53 & 1.67 \\
\hline Combined & 0.46 & 0.41 & 3.30 & 2.67 & 68.9 & 56.6 & 2.72 & 1.99 \\
\hline
\end{tabular}



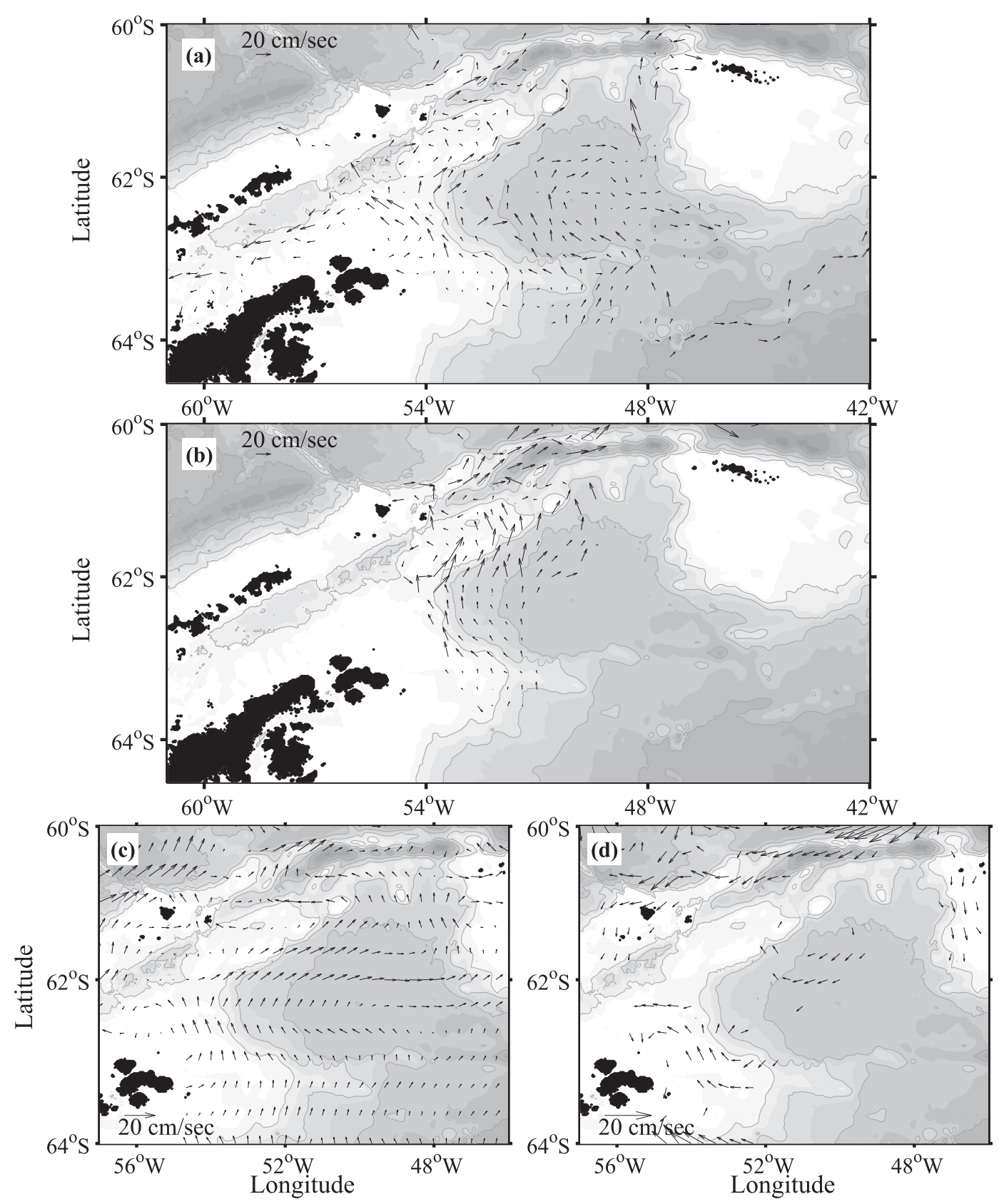

FIG. 4. The mean velocity field calculated from the (a) ADELIE and (b) GENTOO drifters using a $0.2^{\circ} \times 0.4^{\circ}$ grid. (c) The mean velocity fields from the OSCAR product averaged over January to March 2007 and January to March 2012. (d) The difference in velocity between 2007 and $2012\left(\mathbf{u}_{2007}-\mathbf{u}_{2012}\right)$, with velocities plotted if they have a magnitude greater than $3 \mathrm{~cm} \mathrm{~s}^{-1}$. Contour lines are every $1000 \mathrm{~m}$.

given location and are less efficient mixers of tracers (Ferrari and Nikurashin 2010). Finally, we note that the statistical properties in geographic coordinates are more isotropic in 2012, which is consistent with the ASC's offshore position and a reduction in bathymetric control.

A striking feature of the binned velocity fields, shown in Figs. $4 \mathrm{a}$ and $4 \mathrm{~b}$, is the reduced spatial coverage of the GENTOO drifters in 2012, in particular the absence of drifters in Bransfield Strait or in the eastern Powell basin (Fig. 4b). Another notable difference is that in 2012, the drifter trajectories followed a northward path along the western side of the Powell basin, while during 2007 a large portion of the drifters were carried to the northwest away from the Powell basin toward Bransfield Strait (Fig. 4). The spatial structure of eddy kinetic energy (EKE) and mean kinetic energy (MKE) is shown in Fig. 5, where 

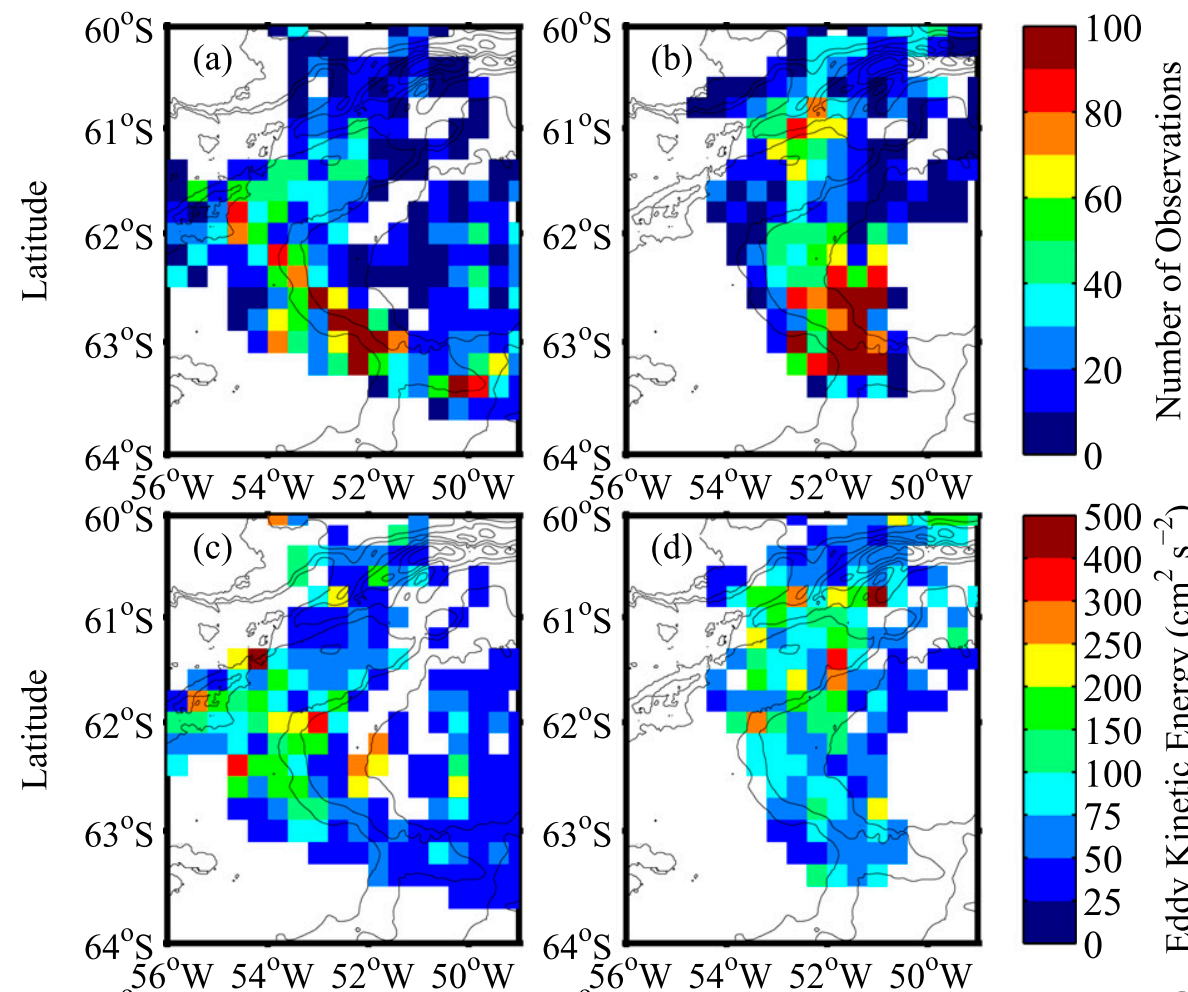

$56^{\circ} \mathrm{W} 54^{\circ} \mathrm{W} 52^{\circ} \mathrm{W} 50^{\circ} \mathrm{W}$
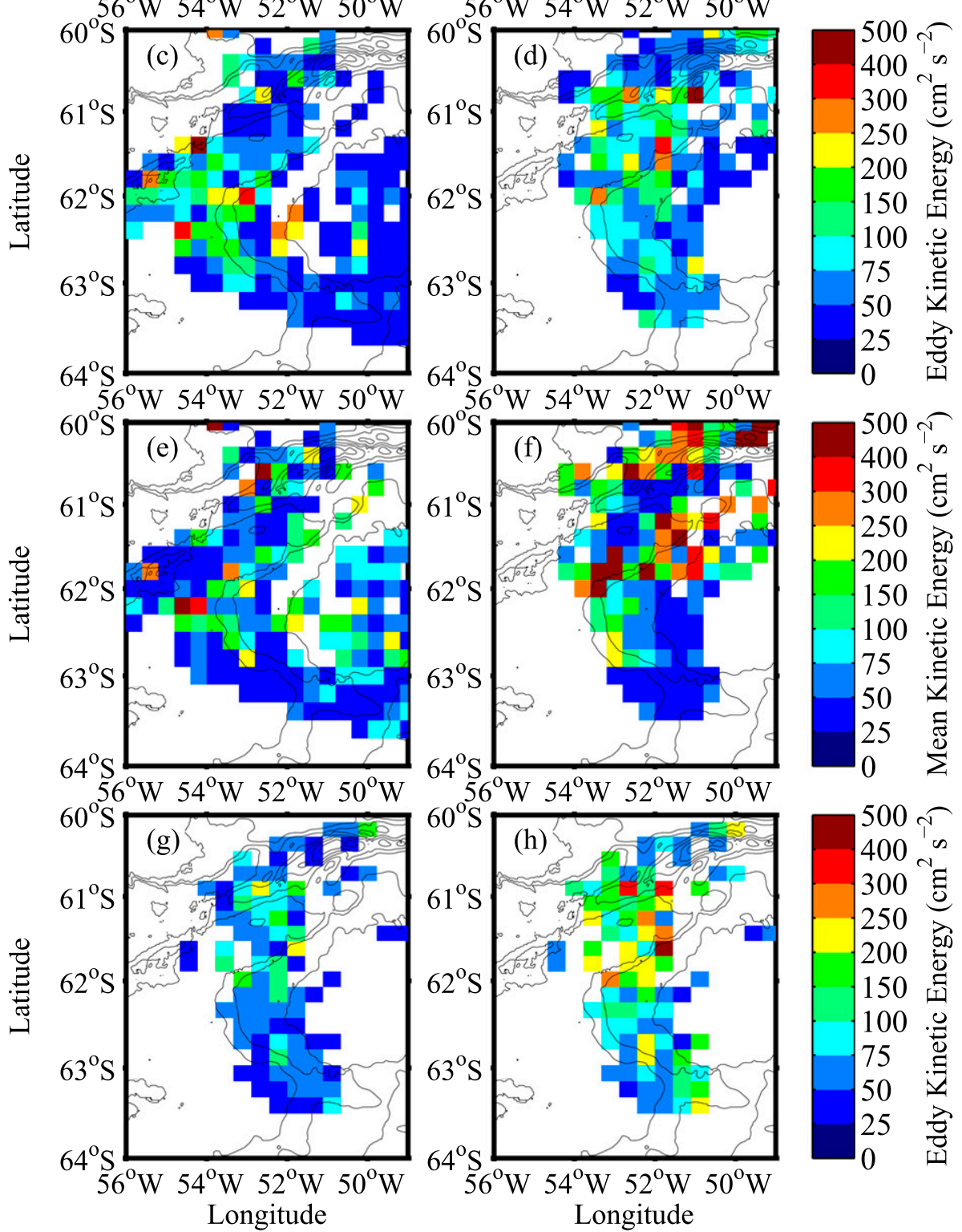

FIG. 5. Statistical properties of the (left) ADELIE and (right) GENTOO drifter trajectories: (a),(b) total number of observations, (c),(d) eddy kinetic energy $\left(\mathrm{cm}^{2} \mathrm{~s}^{-2}\right)$, and (e),(f) mean kinetic energy $\left(\mathrm{cm}^{2} \mathrm{~s}^{-2}\right)$. The $(\mathrm{g})$ lower and (h) upper $95 \%$ confidence intervals for GENTOO EKE. The contour lines are every $1000 \mathrm{~m}$. 


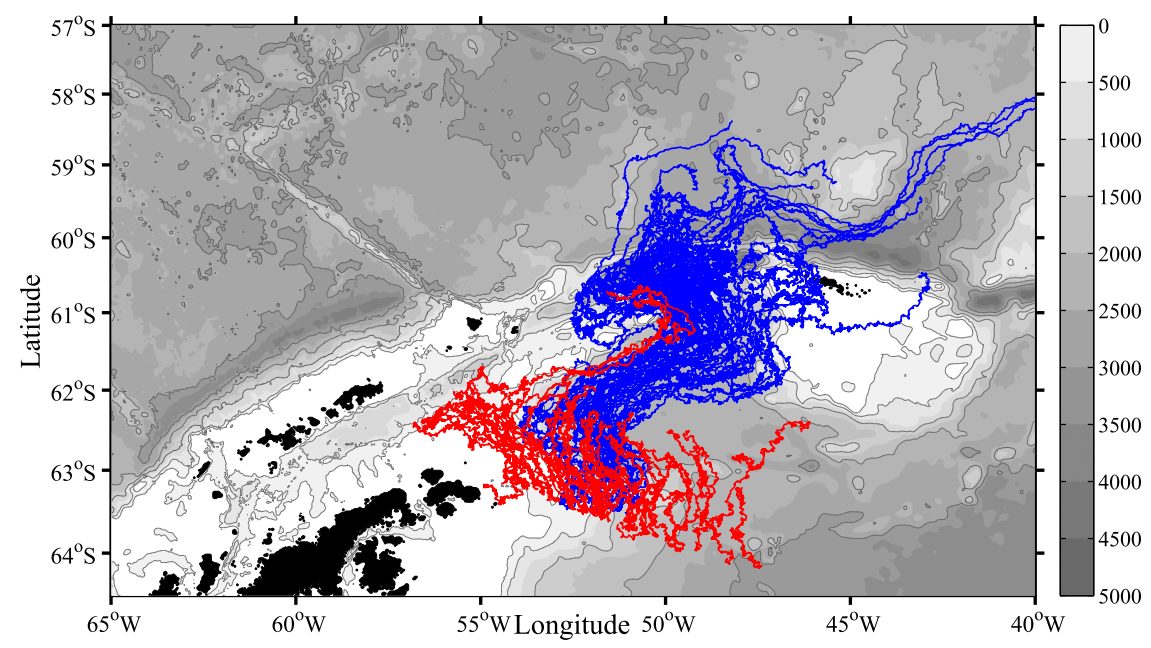

FIG. 6. Virtual drifter trajectories advected by the OSCAR velocity fields following a release on (red) 8 Feb 2007 and (blue) 24 Jan 2012. The drifters are advected for a period of 150 days or, in 2007, until data loss due to sea ice encroachment. The 500-, 1000-, 2000-, 3000-, and 4000-m isobaths are contoured. Compare with the observed trajectories in Fig. 3.

$\operatorname{MKE}(\mathbf{x})=\frac{1}{2}\left(\bar{u}^{2}+\overline{\boldsymbol{v}}^{2}\right), \quad \operatorname{EKE}(\mathbf{x})=\frac{1}{2}\left(\overline{u^{\prime 2}}+\overline{v^{\prime 2}}\right)$,

where overbars indicate a time average. Differences in drifter trajectories make a direct comparison difficult; however, both EKE and MKE are elevated over the southern boundaries of the SSR in 2012. The transition region between the Weddell and Scotia Seas, well resolved in 2012, is characterized by strong mean flows but relatively low EKE, as expected by a flow that is stabilized by a steep continental slope. The highest MKE values in 2012 are found over the SSR, near a trough located at $52^{\circ} \mathrm{W}$. The $95 \%$ confidence intervals are computed for the GENTOO EKE using a bootstrapping technique following Thompson et al. (2009; Figs. 5g,h). See Thompson et al. (2009) for the ADELIE error computations.

\section{c. Modeled drifters}

With the intention of using the OSCAR surface velocity fields to explore a longer time series of Weddell Sea surface circulation variability, we first validate the OSCAR product against the observed drifter trajectories in 2007 and 2012. Virtual drifters were released on 8 February 2007 and 24 January 2012 and were then advected forward in time for a period of 150 days using the OSCAR surface velocities (Fig. 6). The particle advection scheme is the same as the one employed by Renner et al. (2012), including the magnitude of the random white noise added at each time step. The 2007 trajectories (red) show a bifurcation point at $62.5^{\circ} \mathrm{S}, 55^{\circ} \mathrm{W}$ that is consistent with the ADELIE drifter trajectories (Fig. 6). Almost all 2007 drifters released shoreward of the shelf break (500-m isobath) are diverted into Bransfield Strait, while those released farther offshore continue around Powell basin and Hesperides Trough. For the 2007 deployment, the OSCAR drifters cannot be advected for the full 150 days because of encroachment by sea ice and subsequent loss of OSCAR velocities. This loss of the modeled drifters is consistent with the observed slower advection of the ADELIE drifters and their limited export from the Weddell Sea. The virtual drifters released in 2012 realize trajectories that are farther offshore than in 2007.

To confirm that these differences in trajectories are robust, we repeated the virtual drifter experiment 200 times. The addition of random noise leads to changes in the trajectories, which allow us to present confidence intervals: the upper and lower $5 \%$ of the various diagnostics in Table 1 . The mean isobaths for the modeled deployments are $1798 \pm 921 \mathrm{~m}$ in 2007 and $2494 \pm 456 \mathrm{~m}$ in 2012. Some discrepancies between the modeled and observed trajectories exist. For instance, the modeled trajectories do not capture the cross-slope transport onto the SSR in 2012 (Fig. 6), and therefore the average depth is deeper than in the GENTOO drifters. Also, in 2012 the modeled drifters are not overtaken by sea ice, which leads to a longer lifespan and a smaller standard deviation. In 2007, the sea ice overtakes the modeled drifters more rapidly than in the ADELIE deployment, which reduces the lifespan compared with the ADELIE trajectories. Despite these differences, the relative position of the ADELIE and GENTOO deployments is maintained in the modeled drifter deployment. Thus, for the purpose of comparing the cross-slope shifts of the ASC, the OSCAR velocity fields can be used.

A second set of virtual drifter experiments were carried out to test the sensitivity of the trajectories, and 
especially differences between ADELIE and GENTOO deployments, to initial conditions. These perturbation experiments used surface velocity fields from 2007 and 2012 but employed the same baseline starting positions, which coincide with the GENTOO deployment locations on 7 February. From the baseline date and locations, each run involved a random perturbation of the initial drifter positions in both space, a maximum of $\pm 0.05^{\circ}$ latitude and $\pm 0.1^{\circ}$ longitude, and time, a maximum of \pm 2 days. We find that mean velocities over all trajectories and the advection period vary little, ranging from 0.200 to $0.204 \mathrm{~m} \mathrm{~s}^{-1}$ in 2012 and from 0.193 to $0.198 \mathrm{~m} \mathrm{~s}^{-1}$ in 2007 . The mean isobath ranges from 2464 to $2771 \mathrm{~m}$ in 2012 and from 1796 to $2230 \mathrm{~m}$ in 2007 . Finally, we completed an additional 125 virtual drifter experiments from these same start locations but without the spatial/temporal perturbation to determine the degree of inherent variability. Diagnostics from the perturbation experiments all fall within $4 \%$ of the unperturbed experiments. Most importantly, neither the mean velocities nor the mean depths of the 2012 and 2007 perturbation deployments overlap. This indicates that differences in the ADELIE and GENTOO trajectories represent a physical change in the surface circulation and are not simply related to advection by a chaotic flow.

Finally, we compared the OSCAR velocity fields for 2007 and 2012; the mean velocity and the difference in velocities are shown in Figs. $4 \mathrm{c}$ and $4 \mathrm{~d}$, respectively. In the latter case, only velocities that exceed $3 \mathrm{~cm} \mathrm{~s}^{-1}$ are plotted. Overall, the circulation in these $2 \mathrm{yr}$ is similar, dominated by a cyclonic flow around Powell basin. Changes in the surface circulation are largely confined to the regions near the shelf break, indicative of modifications to the boundary currents in this region. The major changes include a dipole located over the continental shelf near Joinville Island, indicating a strengthening of the CC in 2007, and a cyclonic feature at the eastern edge of the SSR, suggesting a strengthening of the ASC south of the SSR in 2012 (Fig. 4d). We note that narrow boundary currents will not be fully resolved in the $1 / 3^{\circ}$ OSCAR fields, so there may be additional structure or more intense changes to the CC and ASC that are not captured. For example, the GENTOO drifters experience a large cross-slope advection over the southern SSR between 18 and 23 February, which is not captured in the remotely sensed OSCAR velocities.

\section{Surface export}

\section{a. Links to environmental forcing}

As summarized above, the ADELIE drifters entrained in the ASC largely remained shoreward of the 1000-m isobath prior to reaching the SSR. Thompson et al. (2009) determined that the $\mathrm{CC}$ joined with the ASC in 2007 north of Joinville Ridge, where the continental slope steepens. The GENTOO trajectories covered a larger portion of the continental slope over the western Powell basin, with two main cores along the 1000- and 2000-m isobaths. We propose that this change in the surface circulation resulted from a weaker CC and an intensification and offshore shift of the ASC in 2012, as compared with 2007. Here, we make use of other existing datasets to support this claim.

Atmospheric forcing is likely to have the primary control over variability in the surface circulation. The most direct measure of the surface forcing is the wind stress curl over the Weddell Sea, and we focus on the gyre-integrated wind stress (Fig. 7a) due to the sensitivity of the gyre's baroclinic circulation to this forcing (Gordon et al. 1981; Meredith et al. 2008). Additionally, we consider the relationship between the surface wind stress and larger-scale climate indices including SAM and ENSO (Figs. 7b,c). The correlation between the 3-month running average SAM index and the 3-month running average wind stress curl is -0.34 with a significance of $p<0.05$. Similarly, we find a correlation between the wind stress curl and ENSO (also a 3-month running average) of 0.16 with a significance of $p<0.05$. Correlations were computed for various lags, but the correlation is strongest at zero lag. Beyond the stronger correlation with SAM, the primary frequency of variability in the wind stress curl matches more closely with SAM variability, whereas ENSO variability has less power at higher frequencies (Fig. 7).

Throughout 2012, the sea ice extent was farther northward than in 2007 (Fig. 8). This distribution is consistent with elevated southerly winds (not shown) and stronger cyclonic wind stress curl during 2012, assuming that the sea ice distribution is responding to both atmospheric wind forcing and advection by the surface currents. Note that the sea ice extent is close to the drifter positions as they traverse the SSR on 20 February 2012 (Fig. 8). The SST is another indication of environmental conditions during the deployments. SST recorded from the drifters (Fig. 9) shows good agreement with remotely sensed SST data (not shown). SST recorded by the drifters in 2012 (Fig. 9) suggest that sea ice was not actively forming in the northwestern Weddell Sea during this time, but rather was advected into Powell basin. This provides further evidence that the cyclonic circulation was enhanced in 2012. During 2007 (Fig. 9a), SST is between $-0.5^{\circ}$ and $0^{\circ} \mathrm{C}$ in the core of the $\mathrm{CC}$ and ASC, with cooler temperatures over the continental shelf. Warmer temperatures $\left(\sim 0.25^{\circ} \mathrm{C}\right)$ are found in the persistent eddy south of Clarence Island; there are only a few drifter trajectories that consistently show temperatures 


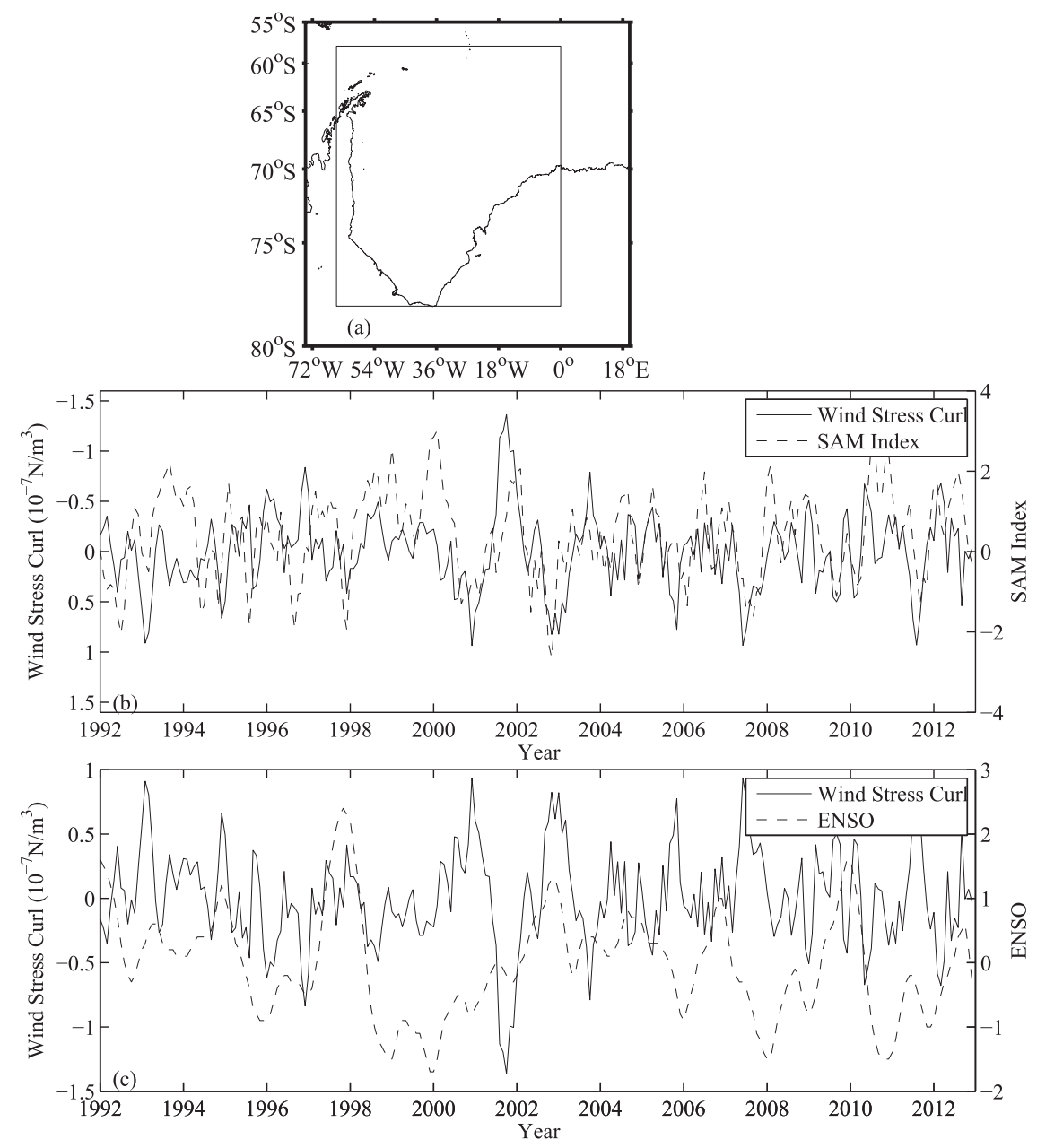

FIG. 7. (a) Map of the Weddell Gyre in which the box represents the averaging region for the wind stress curl shown in the lower panels. The contour line is drawn at sea level. Time series of wind stress curl over Weddell Sea compared with the (b) SAM index and (c) ENSO. The correlation between SAM and wind stress curl is -0.34 and between El Niño and wind stress curl is 0.16 both with $p<0.05$.

over $0^{\circ} \mathrm{C}$. In 2012 (Fig. 9b), SST within the ASC is roughly $0.5^{\circ} \mathrm{C}$ warmer. These warmer temperatures are especially evident over the SSR, where SST values are consistently near $1^{\circ} \mathrm{C}$ around the Hesperides Trough.

\section{b. Export variability from modeled drifters}

Drifter data collected in 2007 and 2012 provide two realizations of the northwestern Weddell Gyre's surface circulation. Agreement between the trajectories derived from the OSCAR data and the ADELIE/GENTOO drifter trajectories gives us confidence to explore variability in other years. While the relationship between observed differences in the drifter trajectories and atmospheric forcing is suggestive of a causal link, it is necessary to test this hypothesis using a longer time series. In this section, we present an analysis of the OSCAR surface velocity dataset in the years 2000, 2002, and 2007 through 2013; use of these years is based on data availability. This analysis follows the work of Renner et al. (2012); however, here we use velocities derived from observational data rather than simulated velocity fields. We note that although the OSCAR data do not resolve mesoscale variability in this region, the observed velocities arise from interactions between mesoscale motions and the larger-scale mean circulation.

For each experiment, virtual drifters were released on 7 February along the GENTOO deployment line A. The date 7 February was chosen both to coincide with the ADELIE deployments and because it allows for maximum OSCAR data availability. Data availability is limited primarily by sea ice cover. Virtual drifters were advected for a period of 45 days; 400 drifters were deployed each year with 10 drifters released at each GENTOO deployment location. Different trajectories 

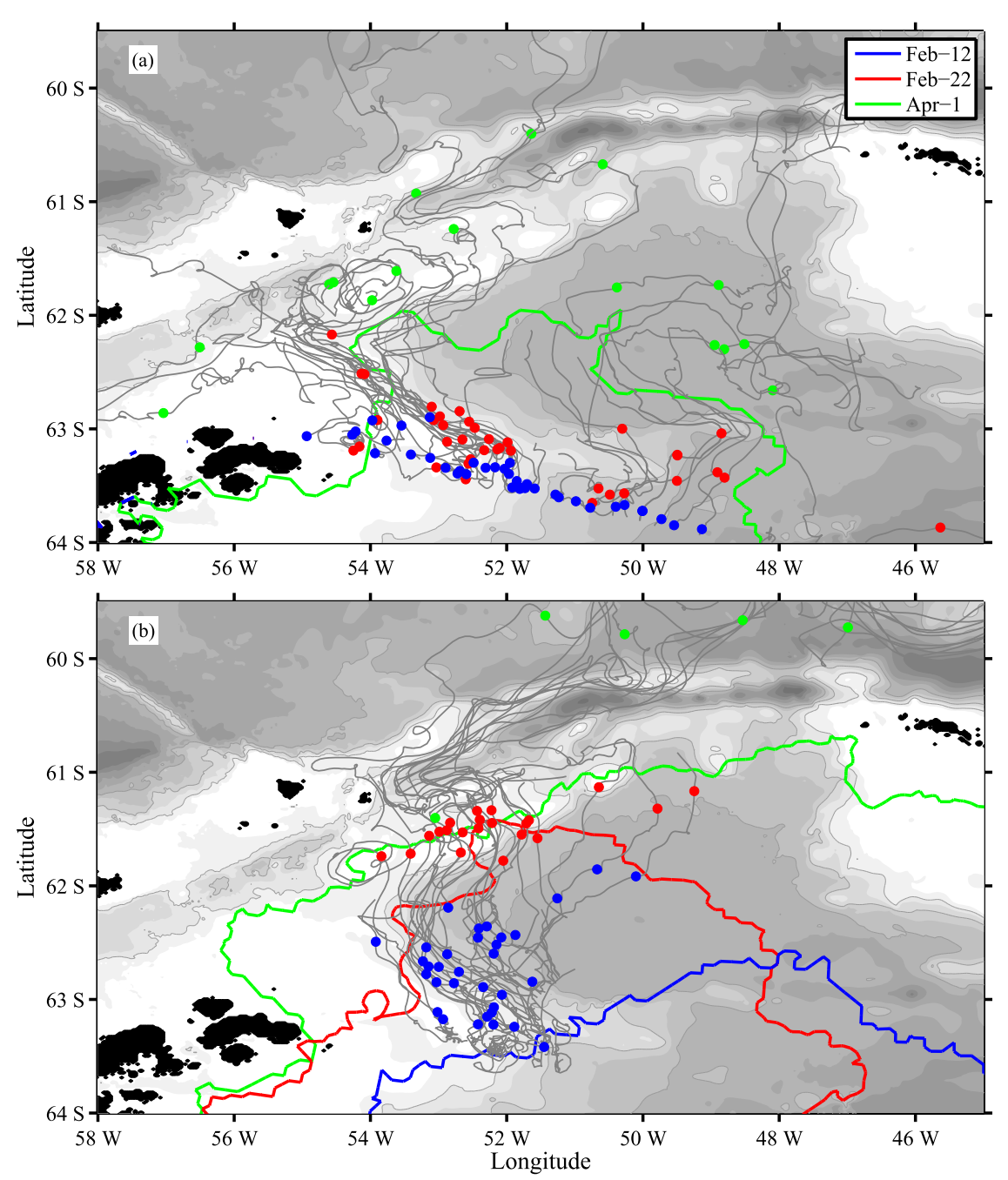

FIG. 8. (a) Northern extent of the $10 \%$ sea ice concentration during the 2007 ADELIE deployment on 12 February (blue), 22 February (red) and 1 April (green). (b) As in (a), but for the 2012 GENTOO deployment. In both panels colored dots indicate drifter positions on these same dates. Drifter trajectories are shown as gray curves. The 500-, 1000-, 2000-, 3000-, and 4000-m isobaths are contoured. The sea ice extent was south of $64^{\circ} \mathrm{S}$ on 12 and $22 \mathrm{Feb} 2007$.

arise from the same deployment location because of the random noise that is applied during the advection algorithm. We focus on two diagnostics, the average speed of the drifters and the mean isobath, as computed in section $3 \mathrm{~d}$. Figure 10 shows the time series of the mean speed (Fig. 10a) and mean isobath (Fig. 10b) for the $9 \mathrm{yr}$, along with interannual variability in the wind stress curl. In each panel, the wind stress represents an average over a 3-month period. To account for lags between changes in wind stress and changes in the surface circulation, correlations were calculated at various temporal lags. The 3-month periods plotted in Fig. 10, different for each panel, represent the strongest correlation.

Figure 10a compares the average speed of the drifter to wind stress curl averaged over January-March (JFM).
Over the 9 years available, the correlation is -0.79 , with a significance of $p<0.05$. Note that a negative wind stress curl is associated with a strengthening of the cyclonic circulation of the gyre. The peak in correlation during JFM indicates that there is little lag between the changes in wind stress curl and the average speed of the ASC in the Weddell Sea. This result is in agreement with the classic picture of the ASC being a primarily winddriven feature (Gill 1973). An enhanced cyclonic wind stress will lead to an enhanced sea surface height gradient along the boundary of the Weddell Gyre and a stronger geostrophic flow. In contrast, the average isobath of the drifter trajectories is found to have its strongest correlation with wind stress curl calculated over October-December (OND), with a correlation of 0.63 with a significance of 

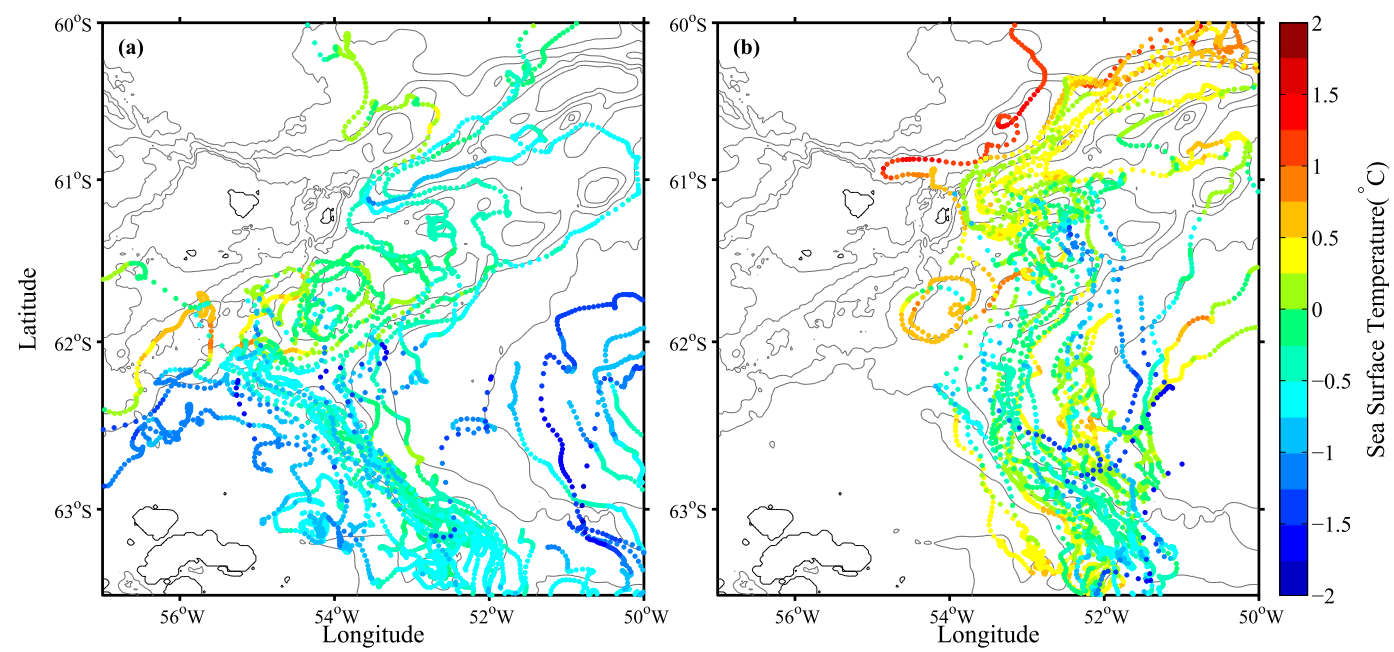

FIG. 9. Sea surface temperature as recorded by the surface drifters from (a) 2007 (ADELIE deployment) and (b) 2012 (GENTOO deployment). The 500-, 1000-, 2000-, 3000-, and 4000-m isobaths are contoured.

$p=0.07$ (Fig. 10b). This suggests that increases in the cyclonic wind stress over the Weddell Sea lead an offshore shift of the ASC by a period of 2 to 5 months. The shift of the ASC is related to the baroclinic adjustment of the gyre circulation and therefore is not an instantaneous process like the Ekman transport. The multimonth lag is in good agreement with a recent idealized analysis of Su et al. (2014), as discussed below.
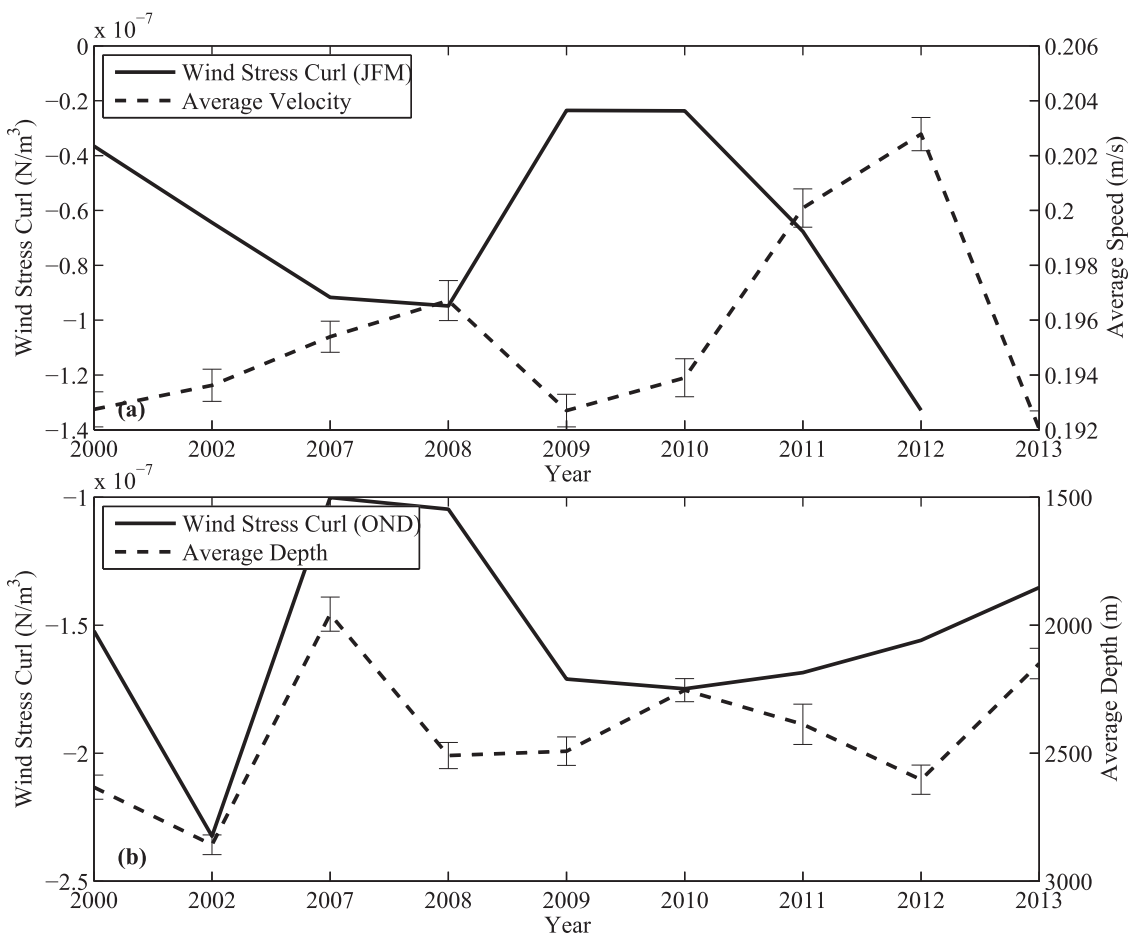

FIG. 10. (a) Time series of wind stress curl averaged over the Weddell Gyre during JFM (solid curve) and the mean speed of virtual drifters (dashed curve) released in the same years and advected by the OSCAR surface velocity product. (b) Time series of wind stress curl averaged over the Weddell Gyre during OND (solid curve) and the average depth of the virtual drifters (dashed curve). Correlation between JFM wind stress curl and average velocity is -0.79 with significance $p<0.05$. Correlation between OND wind stress curl and average depth is 0.63 with significance $p=0.07$. The error bars shown are the $95 \%$ confidence intervals computed from the mean standard error. 

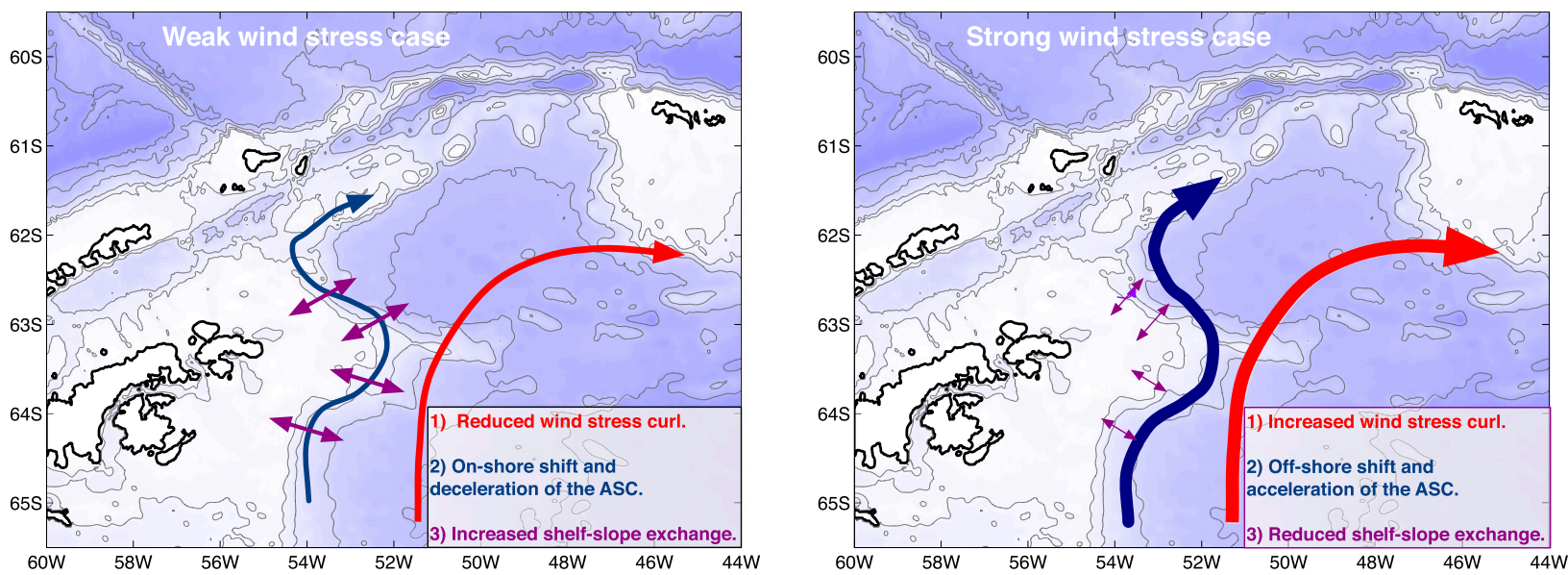

FIG. 11. Schematic summarizing the impact of changes in Weddell Sea wind stress forcing on the position and strength of the Antarctic Slope Current as well as cross-shelf/slope transport properties.

\section{Discussion and conclusions}

\section{a. Links to boundary current variability}

The two drifter datasets discussed in this study offer a first observational glimpse at interannual variability in the ASC boundary current system in the northwestern Weddell Sea. Variability in both the speed and position of these currents at time scales spanning interannual, seasonal, and shorter periods have become evident from recent studies (Gordon et al. 2010; Jullion et al. 2010). The coupling between Weddell Sea wind stress forcing, fluctuations in boundary current characteristics, and export properties to the Scotia Sea is well documented (Gordon et al. 1981; Martinson et al. 1981). Meredith et al. (2008) pointed out that modifications in the gyre's baroclinicity, related to a doming of isopycnals, could impact isopycnal slopes and outcropping at key sills, such as the Orkney Gap. This mechanism was proposed to explain interannual variability in properties of deep water exported to the Scotia Sea. The sense of the doming, specifically both an increase in baroclinic transport as well as an offshore shift of this boundary current, is also consistent with the drifter observations and the OSCAR experiments described in this study.

Changes in the Weddell Gyre's baroclinicity occur primarily within its boundary currents. Jullion et al. (2010) suggested that frictional processes might generate a relatively rapid response to changes in the wind forcing. Analyzing variations in water mass properties at the WOCE SR1b section, they found a strong correlation with Weddell Gyre wind stress at a lag of 5 months. The true response of the gyre would be shorter than this since the 5 months includes advection of the signal to the SR1b section. More recently, Su et al. (2014) considered an idealized Weddell Gyre using a residual mean framework.
This work found that mesoscale activity at the gyre boundary, parameterized as eddy diffusivity, makes the dominant contribution to changes in stratification. Specifically, the model was able to reproduce the observed lag between seasonal changes in the wind forcing and the temperature fluctuations related to migrating isopycnals over the continental slope in the northwestern Weddell Sea. Using the OSCAR data, we also recover a 2- to 5-month lagged correlation between wind stress curl and the position of the ASC, as determined by the mean depth of deployments in various years.

Together these studies suggest a sensitivity of the ASC to surface wind forcing that is summarized in Fig. 11. In years when the wind stress curl intensifies, the cyclonic circulation of the Weddell Sea, and in particular the ASC, accelerates, which increases the probability that surface waters entrained in the ASC are delivered to the Scotia Sea over the SSR. Yet, the intensification of the ASC is also accompanied by an offshore shift of the current, such that in years of strong wind stress curl delivery of Weddell shelf waters is likely reduced. This occurs because the intensification of the ASC results in a steepening of isopycnals across the boundary current and a deeper isopycnal outcropping on the continental slope that shifts the ASC away from the shelf break (Meredith et al. 2008; Su et al. 2014). An additional effect is that a stronger mean flow will produce a more effective barrier to cross-front transport as lateral advection of mesoscale eddies reduces their efficiency to locally stir tracers. This meanflow suppression of mixing has been shown to be relevant for cross-stream transport in the ACC (Ferrari and Nikurashin 2010).

Thus, we propose that a strengthening of the cyclonic wind stress curl results in a reduction in surface water cross-shelf exchange in the northwestern Weddell Sea. 
This relationship finds support in the study of Thompson and Youngs (2013), which showed that surface chlorophyll$a$ concentrations in both the Powell basin and the Scotia Sea covary with the SAM index. In particular, chlorophyll$a$ concentrations are enhanced in years of weaker SAM index, which would be consistent with a weaker ASC that is located farther onshore. In this case, the ASC, which is the primary source of iron for the Scotia Sea south of the southern ACC front (Tagliabue et al. 2009; Wadley et al. 2014), would have greater access to the shelf where ironrich sediment fertilizes the water column. A weaker ASC would also reduce the effectiveness of this current as a barrier to cross-shelf transport due to weaker isopycnal and potential vorticity gradients (Flexas et al. 2005). In contrast, as the wind stress curl intensifies, the Weddell Sea continues to inject surface waters in the Scotia Sea, but these are less likely to contain iron-rich shelf waters, which may limit primary productivity. This sensitive relationship between boundary current variability and larger-scale ecosystem dynamics requires further study and will require a careful assessment of mesoscale processes that are often poorly resolved in numerical models.

Variability in the drifter trajectories across the different years when OSCAR was available make a convincing case that the large-scale surface circulation is strongly influenced by the wind stress curl. However, it is important to note that the OSCAR data are quite coarse compared with the typical scale of mesoscale features in this region, $10 \mathrm{~km}$ or even smaller over the shelf. Much of the finescale structure of the trajectories is not captured by the virtual drifters. A specific example is the abrupt transport of 10 drifters across the continental slope and onto the continental shelf of the SSR on 20 February 2012. This motion could be related to localized processes such as the interaction of tides with bathymetric features, sea ice, or even large icebergs, which may lead to large deviations in the modeled drifter trajectories.

\section{b. Summary}

The GENTOO drifter study represents the rare opportunity to repeat a Lagrangian experiment in a region with limited observations of temporal variability on both short (mesoscale) and long (interannual) scales. The ASC and CC are critical components of the exchange of Antarctic marginal water masses with the greater Southern Ocean, and their variability is poorly understood.

Acknowledging the modified deployment strategy enforced by the anomalous sea ice extent in 2012, drifter trajectories between 2007 and 2012 exhibited substantial differences. The most prominent of these changes was an intensification of the CC in 2007 and an offshore shift and strengthening of the ASC in 2012. Both the intensification of the ASC and its position over deeper waters in 2012 would have limited the exchange of water masses across the shelf break in 2012 and reduced the delivery of shelf waters to the Scotia Sea. This is supported by higher sea surface temperatures in 2012 (Fig. 9) and a reduction in remotely observed chlorophyll levels both in the northwestern Weddell Sea and in the southern Scotia Sea (Thompson and Youngs 2013).

Differences in these circulation properties are linked to atmospheric forcing, specifically the wind stress curl over the Weddell Gyre, and are shown to hold over almost a decade of realizations using virtual drifters advected by the OSCAR surface velocity product. Wind stress curl over the Weddell Gyre correlates well with larger-scale variability in the SAM index (Fig. 7; Jullion et al. 2010; Renner et al. 2012) and also relates to changes in drifter trajectory characteristics, similar to the findings of Renner et al. (2012). Surface circulation properties that vary in response to wind forcing include not only the intensity of the ASC, which is elevated during years of stronger wind stress curl, but also an offshore shift of the ASC. The benefit of using the OSCAR dataset is that despite its relatively coarse resolution, the large-scale velocities that are captured arise from interactions with the smaller-scale mesoscale eddy field.

The relationship between the SAM and the Weddell's regional outflow is intriguing and merits further investigation, especially since the SAM has been linked to anthropogenic forcings (Marshall et al. 2004). We suggest here that an equally important result arising from changes in surface forcing is the impact on cross-frontal exchange that mediates the delivery of unique water properties over the continental shelf to the open ocean (Fig. 11). We suggest that the combination of an enhanced mean flow and an offshore shift suppresses exchange with the shelf, effectively shielding the drifters from the colder and iron-rich shelf waters that the ADELIE drifters traversed in 2007. This shielding is consistent with a potential vorticity framework, with enhanced frontal currents associated with stronger horizontal potential vorticity gradients that separate shelf and slope waters as shown by Flexas et al. (2005).

A challenge, though, is that there is ample evidence that cross-slope and cross-shelf exchange depends on mesoscale processes (Dinniman et al. 2011; Stewart and Thompson 2013) that are difficult to capture in general circulation models. Lagrangian drifters have proven to be an effective means of observing exchange between the Antarctic margins and the greater Southern Ocean near the Antarctic Peninsula, and Lagrangian techniques may have a broader role to play around Antarctica in identifying the surface exchange of glacial meltwater. 
Acknowledgments. We thank everyone who made the GENTOO cruise successful, especially the officers and crew of the RRS James Clark Ross. We are grateful for the financial support of the NOAA Global Drifter Program (GDP) as well as the assistance of Mayra Pazos with the drifter data. Conversations with Alberto Naveira Garabato and Angelika Renner improved this manuscript. The ADELIE and GENTOO cruises were supported by the U.K. Natural Environment Research Council (NERC) through the Antarctic Funding Initiative (NE/C50633X/1 and NE/H01439X/1, respectively). Support for the drifters came from the GDP and the Davidow Discovery Fund. MKY's participation was funded by the J. Weldon Green and Samuel P. and Frances Krown Summer Undergraduate Research Fellowships (SURFs), the George W. Housner Fund, and the James Morgan Fellowship. AFT was supported by NSF Grant NSF OPP-1246460. MMFs participation was supported by an appointment to the NASA Postdoctoral Program at the Jet Propulsion Laboratory/California Institute of Technology, administered by Oak Ridge Associated Universities through a contract with NASA.

\section{REFERENCES}

Ardelan, M. V., O. Holm-Hansen, C. D. Hewes, C. S. Reiss, N. S. Silva, H. Dulalova, E. Steinnes, and E. Sakshaug, 2010: Natural iron enrichment around the Antarctic Peninsula. Biogeosciences, 7, 11-25, doi:10.5194/bg-7-11-2010.

Bauer, S., M. S. Swenson, A. Griffa, A. J. Mariano, and K. Owens, 1998: Eddy-mean flow decomposition and eddy-diffusivity estimates in the tropical Pacific Ocean. J. Geophys. Res., 103, 30 855-30 871, doi:10.1029/1998JC900009.

Bonjean, F., and G. S. E. Lagerloef, 2002: Diagnostic model and analysis of the surface currents in the tropical Pacific Ocean. J. Phys. Oceanogr., 32, 2938-2954, doi:10.1175/1520-0485(2002)032<2938: DMAAOT $>2.0 . \mathrm{CO} ; 2$.

Dee, D., and Coauthors, 2011: The ERA-Interim reanalysis: Configuration and performance of the data assimilation system. Quart. J. Roy. Meteor. Soc., 137, 553-597, doi:10.1002/qj.828.

Dinniman, M. S., J. M. Klinck, and W. O. Smith, 2011: A model study of Circumpolar Deep Water on the west Antarctic Peninsula and Ross Sea continental shelves. Deep-Sea Res. II, 58, 1508-1523, doi:10.1016/j.dsr2.2010.11.013.

Falco, P., A. Griffa, P.-M. Poulain, and E. Zambianchi, 2000: Transport properties in the Adriatic Sea as deduced from drifter data. J. Phys. Oceanogr., 30, 2055-2071, doi:10.1175/ 1520-0485(2000)030<2055:TPITAS > 2.0.CO;2.

Ferrari, R., and M. Nikurashin, 2010: Suppression of eddy mixing across jets in the Southern Ocean. J. Phys. Oceanogr., 40, 1501-1519, doi:10.1175/2010JPO4278.1.

Fitzwater, S. E., K. S. Johnson, R. M. Gordon, K. H. Coale, and W. O. Smith Jr., 2000: Trace metal concentrations in the Ross Sea and their relationship with nutrients and phytoplankton growth. DeepSea Res. II, 47, 3159-3179, doi:10.1016/S0967-0645(00)00063-1.

Flexas, M. M., G. J. F. van Heijst, and R. R. Trieling, 2005: The behavior of jet currents over a continental slope topography with a possible application to the Northern Current. J. Phys. Oceanogr., 35, 790-810, doi:10.1175/JPO2705.1.
Frants, M., and Coauthors, 2012a: Optimal multiparameter analysis of source water distributions in the southern Drake Passage. Deep-Sea Res. II, 90, 31-42, doi:10.1016/j.dsr2.2012.06.002.

_ S. T. Gille, M. Hatta, W. T. Hiscock, M. Kahru, C. I. Measures, B. G. Mitchell, and M. Zhou, 2012b: Analysis of horizontal and vertical processes contributing to natural iron supply in the mixed layer in southern Drake Passage. Deep-Sea Res. II, 90, 68-70, doi:10.1016/j.dsr2.2012.06.001.

Gill, A. E., 1973: Circulation and bottom water production in the Weddell Sea. Deep-Sea Res. Oceanogr. Abstr., 20, 111-140, doi:10.1016/0011-7471(73)90048-X.

Gordon, A. L., D. Martinson, and H. Taylor, 1981: The wind-driven circulation in the Weddell-Enderby basin. Deep-Sea Res., 28A, 151-163, doi:10.1016/0198-0149(81)90087-X.

_ B. Huber, D. McKee, and M. Visbeck, 2010: A seasonal cycle in the export of bottom water from the Weddell Sea. Nat. Geosci., 3, 551-556, doi:10.1038/ngeo916.

Hall, A., and M. Visbeck, 2002: Synchronous variability in the Southern Hemisphere atmosphere, sea ice, and ocean resulting from the annular mode. J. Climate, 15, 3043-3057, doi:10.1175/ 1520-0442(2002)015<3043:SVITSH > 2.0.CO;2.

Hansen, D. V., and P.-M. Poulain, 1996: Quality control and interpolations of WOCE-TOGA drifter data. J. Atmos. Oceanic Technol., 13, 900-909, doi:10.1175/1520-0426(1996)013<0900: QCAIOW $>2.0 . C O ; 2$.

Heywood, K. J., A. C. N. Garabato, D. P. Stevens, and R. D. Muench, 2004: On the fate of the Antarctic Slope Front and the origin of the Weddell Front. J. Geophys. Res., 109, C06021, doi:10.1029/2003JC002053.

Hofmann, E. E., J. M. Klinck, R. A. Locarnini, B. Fach, and E. J. Murphy, 1998: Krill transport in the Scotia Sea and environs. Antarct. Sci., 10, 406-415, doi:10.1017/S0954102098000492.

Jacobs, S. S., 1991: On the nature and significance of the Antarctic Slope Front. Mar. Chem., 35, 9-24, doi:10.1016/ S0304-4203(09)90005-6.

Johnson, E. S., F. Bonjean, G. S. Lagerloef, J. T. Gunn, and G. T. Mitchum, 2007: Validation and error analysis of OSCAR sea surface currents. J. Atmos. Oceanic Technol., 24, 688-701, doi:10.1175/JTECH1971.1.

Jullion, L., S. C. Jones, A. C. Naveira Garabato, and M. P. Meredith, 2010: Wind-controlled export of Antarctic Bottom Water from the Weddell Sea. Geophys. Res. Lett., 37, L09609, doi:10.1029/ 2010GL042822.

Klocker, A., R. Ferrari, and J. H. LaCasce, 2012a: Estimating suppression of eddy mixing by mean flows. J. Phys. Oceanogr., 42, 1566-1576, doi:10.1175/JPO-D-11-0205.1.

,,--- , and S. T. Merrifield, 2012b: Reconciling floatbased and tracer-based estimates of lateral diffusivities. J. Mar. Res., 70, 569-602, doi:10.1357/002224012805262743.

Korb, R. E., M. J. Whitehouse, and P. Ward, 2004: SeaWiFS in the Southern Ocean: spatial and temporal variability in phytoplankton biomass around South Georgia. Deep-Sea Res. II, 51, 99-116, doi:10.1016/j.dsr2.2003.04.002.

Koszalka, I. M., and J. H. LaCasce, 2010: Lagrangian analysis by clustering. Ocean Dyn., 60, 957-972, doi:10.1007/ s10236-010-0306-2.

LaCasce, J., 2008: Statistics from Lagrangian observations. Prog. Oceanogr., 77, 1-29, doi:10.1016/j.pocean.2008.02.002.

Lumpkin, R., and M. Pazos, 2007: Measuring surface currents with surface velocity program drifters: The instrument, its data, and some recent results. Lagrangian Analysis and Prediction of Coastal and Ocean Dynamics, Cambridge University Press, 39-67. 
— N. Maximenko, and M. Pazos, 2012: Evaluating where and why drifters die. J. Atmos. Oceanic Technol., 29, 300-308, doi:10.1175/JTECH-D-11-00100.1.

Marshall, G. J., 2003: Trends in the Southern Hemisphere annular mode from observations and reanalyses. J. Climate, 16, 4134-4143, doi:10.1175/1520-0442(2003)016<4134:TITSAM >2.0.CO;2.

—, P. A. Stott, J. Turner, W. M. Connolley, J. C. King, and T. A. Lachlan-Cope, 2004: Causes of exceptional atmospheric circulation changes in the Southern Hemisphere. Geophys. Res. Lett., 31, L14205, doi:10.1029/2004GL019952.

Martin, J. H., R. M. Gordon, and S. E. Fitzwater, 1990: Iron in Antarctic waters. Nature, 345, 156-158, doi:10.1038/345156a0.

Martinson, D. G., P. D. Killworth, and A. L. Gordon, 1981: A convective model for the Weddell Polynya. J. Phys. Ocean ogr., 11, 466-488, doi:10.1175/1520-0485(1981)011<0466: ACMFTW $>2.0 . \mathrm{CO} ; 2$.

Meredith, M. P., and A. M. Hogg, 2006: Circumpolar response of Southern Ocean eddy activity to a change in the southern annular mode. Geophys. Res. Lett., 33, L16608, doi:10.1029/ 2006GL026499.

_ E. J. Murphy, E. J. Hawker, J. C. King, and M. I. Wallace, 2008: On the interannual variability of ocean temperatures around South Georgia, Southern Ocean: Forcing by El Niño/ Southern Oscillation and the southern annular mode. DeepSea Res. II, 55, 2007-2022, doi:10.1016/j.dsr2.2008.05.020.

Murphy, E. J., S. E. Thorpe, J. L. Watkins, and R. Hewitt, 2004: Modeling the krill transport pathways in the Scotia Sea: Spatial and environmental connections generating the seasonal distribution of krill. Deep-Sea Res. II, 51, 1435-1456, doi:10.1016/ j.dsr2.2004.06.019.

Niiler, P. P., A. S. Sybrandy, K. Bi, P.-M. Poulain, and D. Bitterman, 1995: Measurements of the water-following capability of holeysock and TRISTAR drifters. Deep-Sea Res. I, 42, 1951-1964, doi:10.1016/0967-0637(95)00076-3.

Nøst, O., M. Biuw, V. Tverberg, C. Lydersen, T. Hattermann, Q. Zhou, L. Smedsrud, and K. Kovacs, 2011: Eddy overturning of the Antarctic Slope Front controls glacial melting in the eastern Weddell Sea. J. Geophys. Res., 116, C11014, doi:10.1029/ 2011JC006965.

O'Kane, T. J., R. J. Matear, M. A. Chamberlain, J. S. Risbey, B. M. Sloyan, and I. Horenko, 2013: Decadal variability in an OGCM Southern Ocean: Intrinsic modes, forced modes and metastable states. Ocean Modell., 69, 1-21, doi:10.1016/ j.ocemod.2013.04.009.

Palmer, M., D. Gomis, M. del Mar Flexas, G. Jordà, L. Jullion, T. Tsubouchi, and A. C. N. Garabato, 2012: Water mass pathways and transports over the South Scotia Ridge west of 50W. Deep-Sea Res. I, 59, 8-24, doi:10.1016/j.dsr.2011.10.005.

Patterson, S. L., and H. A. Sievers, 1980: The Weddell-Scotia Confluence. J. Phys. Oceanogr., 10, 1584-1610, doi:10.1175/ 1520-0485(1980)010<1584:TWSC $>2.0 . C O ; 2$.

Renner, A. H. H., S. E. Thorpe, K. J. Heywood, E. J. Murphy, J. L. Watkins, and M. P. Meredith, 2012: Advective pathways near the tip of the Antarctic Peninsula: Trends, variability and ecosystem implications. Deep-Sea Res. I, 63, 91-101, doi:10.1016/ j.dsr.2012.01.009.

Sen Gupta, A., and M. H. England, 2006: Coupled oceanatmosphere-ice response to variations in the southern annular mode. J. Climate, 19, 4457-4486, doi:10.1175/JCLI3843.1.

Simmons, A., S. Uppala, D. Dee, and S. Kobayashi, 2007: ERAInterim: New ECMWF reanalysis products from 1989 onwards.
ECMWF Newsletter, No. 110, ECMWF, Reading, United Kingdom, 25-35.

Simpkins, G. R., L. M. Ciasto, D. W. J. Thompson, and M. H. England, 2012: Seasonal relationship between large-scale climate variability and Antarctic sea ice concentration. J. Climate, 25, 5451-5469, doi:10.1175/JCLI-D-11-00367.1.

Smith, W. H. F., and D. T. Sandwell, 1997: Global seafloor topography from satellite altimetry and ship depth soundings. Science, 277, 1957-1962, doi:10.1126/science.277.5334.1956.

Spreen, G., L. Kalechke, and G. Heygster, 2008: Sea ice remote sensing using AMSR-E 89-GHz channels. J. Geophys. Res., 113, C02S03, doi:10.1029/2005JC003384.

Stewart, A. L., and A. F. Thompson, 2013: Connecting Antarctic cross-slope exchange with Southern Ocean overturning. J. Phys. Oceanogr., 43, 1453-1471, doi:10.1175/JPO-D-12-0205.1.

Su, Z., A. L. Stewart, and A. F. Thompson, 2014: An idealized model of Weddell Gyre export variability. J. Phys. Oceanogr., 44, 1671-1688, doi:10.1175/JPO-D-13-0263.1.

Tagliabue, A., L. Bopp, and O. Aumont, 2009: Evaluating the importance of atmospheric and sedimentary iron sources to Southern Ocean biogeochemistry. Geophys. Res. Lett., 36, L13601, doi:10.1029/2009GL038914.

Thompson, A. F., and M. K. Youngs, 2013: Surface exchange between the Weddell and Scotia Seas. Geophys. Res. Lett., 40, 5920-5925, doi:10.1002/2013GL058114.

—, K. J. Heywood, A. H. H. Renner, and A. Trasviña, 2009: Surface circulation at the tip of Antarctic Peninsula from drifters. J. Phys. Oceanogr., 39, 3-36, doi:10.1175/2008JPO3995.1.

,-- S. Schmidtko, and A. L. Stewart, 2014: Eddy transport as a key component of the Antarctic overturning circulation. Nat. Geosci., 7, 879-884, doi:10.1038/ngeo2289.

Thompson, D. W. J., and S. Solomon, 2002: Interpretation of recent Southern Hemisphere climate change. Nature, 296, 895-899, doi:10.1126/science.1069270.

Thorpe, S. E., K. J. Heywood, D. P. Stevens, and M. A. Brandon, 2004: Tracking passive drifters in a high resolution ocean model: Implications for interannual variability of larval krill transport to South Georgia. Deep-Sea Res. I, 51, 909-920, doi:10.1016/j.dsr.2004.02.008.

, E. J. Murphy, and J. Watkins, 2007: Circumpolar connections between Antarctica krill populations (Euphasia superba Dana): Investigating the roles of ocean and sea ice transport. Deep-Sea Res. I, 54, 792-810, doi:10.1016/j.dsr.2007.01.008.

Wadley, M. R., T. D. Jickells, and K. J. Heywood, 2014: The role of iron sources and transport for Southern Ocean productivity. Deep-Sea Res. I, 87, 82-94, doi:10.1016/j.dsr.2014.02.003.

Whitworth, T., and A. Orsi, 2006: Antarctic Bottom Water production and export by tides in the Ross Sea. Geophys. Res. Lett., 33, L12609, doi:10.1029/2006GL026357.

- W. D. Nowlin Jr., A. H. Orsi, R. A. Locarnini, and S. Smith, 1994: Weddell Sea shelf water in the Bransfield Strait and Weddell-Scotia Confluence. Deep-Sea Res. I, 41, 629-641, doi:10.1016/0967-0637(94)90046-9.

, A. Orsi, S.-J. Kim, W. Nowlin, and R. Locarnini, 1998: Water masses and mixing near the Antarctic Slope Front. Ocean, Ice, and Atmosphere: Interactions at the Antarctic Continental Margin, Geophys. Monogr., Vol. 75, Amer. Geophys. Union, 1-27, doi:10.1029/AR075p0001.

Zhou, M., Y. Zhu, R. D. Dorland, and C. I. Measures, 2010: Dynamics of the current system in the southern Drake Passage. Deep-Sea Res. I, 57, 1039-1048, doi:10.1016/j.dsr.2010.05.012. 